\title{
Determining the Influence of Ship Hull Deformations Caused by Draught Change on Shaft Alignment Application using FE Analysis
}

Chul-Oh Seo ${ }^{1}$, Byongug Jeong ${ }^{2}$, Jung-Ryul Kim ${ }^{3}$, Myeongho Song ${ }^{4}$, Jung-Ho Noh ${ }^{5}$, Jae-ung Lee*

*Division of Marine Information Technology, Korea Maritime and Ocean University, 727 Taejongro, Yeongdo-gu, Busan, 49112, Republic of Korea

${ }^{1}$ Daewoo Shipbuilding \& Marine Engineering Co., Ltd. (DSME), Geoje-daero 3370, Geoje-si, Gyeongsangnam-do, 53302, Republic of Korea

${ }^{2}$ Department of Naval Architecture, Ocean and Marine Engineering, University of Strathclyde, 100 Montrose Street, Glasgow, G4 OLZ, UK

${ }^{3}$ Department of Marine System Engineering, Korea Maritime and Ocean University,

Taejong-ro 727, Yeongdo-Gu, Busan, 49112, Republic of Korea

${ }^{4}$ Ship Repair Supporting Centre, Mokpo National Maritime University,

91, Haeyangdaehak -ro, Mokpo-si, Jeollanam-do, 58628, Republic of Korea

${ }^{5}$ Department of Ship Operation, Korea Maritime and Ocean University,

Taejong-ro 727, Yeongdo-Gu, Busan, 49112, Republic of Korea

*corresponding author; e-mail: julee@kmou.ac.kr, phone: +82(0)51 4104662 


\begin{abstract}
This paper was to address the shortcomings of current design practice to evaluate the stability of the shaft alignment for a 300,000 DWT Very Large Crude Oil Carrier. An enhanced approach using FE was applied to identify the influence of hull deformation on the alignment of the shafting system. The effectiveness of this method was demonstrated in comparison with Jack up technique. Analysis results showed that the hull deformation could be a key factor affecting the offset distortion of each bearing supporting the shaft line. Moreover, it was confirmed that the deformation pattern of cargo hold was opposite to the deformation of engine room structure when hull deformation occurred due to draught change of the case ship. As new research findings, they are believed to contribute significantly to the prevention of shaft damage associated with hull deformations, thereby improving the reliability of shaft alignment for similar types of vessels.
\end{abstract}

Keywords: Hull deformation, Shaft alignment, Finite element method, Jack up method

\title{
1. Introduction
}

The recent trend in increasing ship size has been found to cause shaft bearing damage due to an increase in hull deformation which contributes to the change in bearing height (hereinafter referred to as offset) to support the shafting system. Given this, ship-owners, shipyards and classification societies are striving to find a solution by strengthening the analysis, installation and verification process for proper shaft alignment, taking into account hull deformation effects.

The first study on the reliability of ship propeller shaft systems was carried out by the US Navy in the late 1950 s, and in the early 1970 s, extensive research was undertaken to establish the pragmatic guidelines for determining the optimal position of individual bearings (Rudolph, 1959; Anderson and 
Zrodowski, 1959; Lehr and Parker, 1961; Mann, 1964; Mann, 1965a, 1965b; Mott et al., 1967; Wilkin and Strassheim, 1973)

At present, the shaft alignment calculation requires the high performance of computer software by making the total stiffness matrix $(2 n+2)$ for finite element analysis based on a square matrix whose elements are divided by ' $n$ ' considering the change of the axial section, the bearing support point, and the external force. In the late 1970s, along with the development of computer programs, a series of studies (DnV, 1975; Jeon et al., 1978; Park and Lee, 1979; Doikos, 1979; Moon and Jeon, 1981; Larsen, 1981a, 1981b) played an important role in establishing shaft alignment exercises.

Prior to 1950, the straight alignment method (Jeon, 1986) was used in which the centres of all support bearings were aligned on the same straight line when aligning shafts.

However, the straight alignment method has some disadvantages: particularly, irregular load distribution to each support bearing; deformation of bearing offsets due to hull deformation; natural wear due to long-term operation. As a result, the centres of all bearings could not be placed in the same straight line. Given this, the method of the free-curved alignment (Moon and Jeon, 1981; SNAME, 2007) was introduced as an alternative method,

The free-curved alignment refers to a method of arranging the vertical offset of each support bearing in line with a virtual reference line to distribute the shaft load on each bearing evenly within the allowable load range.

In addition, several improved methods have been introduced to increase the reliability of shaft alignment: a gap-sag method for applying a free-curved alignment method for actual sorting; Hydraulic jack method for measuring bearing reaction force; Strain gauge methods (Grant, 1980; Forrest and Labasky, 1981; Cowper et al., 1999; MDT, 2012) as well as slope boring methods that increase the contact area between shaft and bearing in stern tube bearings (Kozousek, 2000).

On the other hand, the hull deformation has tended to increase compared to the past due to the increase of the hull flexibility following the hull optimization which started in the 1990s. 
In other words, the plate of the hull including the engine room structure is designed to be thinner for hull optimization and is easy to deform whereas the propulsion shafting system has the opposite trend due to increase of engine power (NK, 2006).

Therefore, if the propeller shaft alignment calculation is performed without considering the hull deformation, ship designers may not be able to estimate the range of changes in bearing reaction forces caused by the hull deformation. As a result, even in small deformations of the hull, the bearing reaction force can change significantly, thereby leading to shaft bearing damage.

This phenomenon, due to the trend of becoming larger size of merchant ships, caused various forms of damage throughout the bearings supporting the shaft system, such as stern tube bearings and main engine bearings.

Meanwhile, accidents associated with damage to the main engine bearings have been reported to be significantly reduced since the main engine manufacturer has recognized load distribution problems with shaft alignment in the aftmost crankshaft bearings and the aftmost engine bearings (Wärtsilä, 2007; MDT, 2014).

Since the 2000s, however, due to the growth of the world economy and the advent of ultra large ships, accidents caused by shaft alignment have started to occur again.

These accidents are mainly associated with the effect of hull deformation, which is mainly due to heat generation or abnormal wear in the stern tube bearings. During this period, various studies related to shaft alignment such as hull deformation and shaft support stiffness have been performed (Sverko, 2003; Sverko, 2005; Murawski, 2005; Lee and Kim, 2005a, 2005b; Lee et al., 2005; DnV, 2006; Lee et al., 2006; Lee, 2006; ABS, 2006; Lei et al., 2010).

In addition, the classification societies also provided several methods of measuring hull deformations using strain gauges and proximity sensors with various studies on shaft alignment considering changes in bearing stiffness for bearings and structures supporting shaft systems, and prevention of damage to after stern tube bearing. Based on various research results such as lubrication analysis of stern tube 
bearings and analysis of ship accident cases, the classification rules and relevant guidelines are proposed to secure propulsion shaft stability (NK, 2006; BV, 2015; ABS, 2015; DnVGL, 2019).

Two approaches were used to analyse the proper alignment of the shafting system: a holistic method that takes into account the entire propulsion system; the other is a partial method that considers only certain bearings and parts of the shafts within the bearings (Bradshaw, 1995).

In addition, the approach of the shaft alignment has been classified into static and dynamic analyses in detail. In the dynamic analysis, the effect of the film between the shaft and the bearing gap and the propeller eccentric force determined from the propeller shape and the ship's shape are further considered in comparison with the static analysis.

In general, the dynamic analysis method is known to have relatively more difficulties. Particularly, there is a problem of rational estimation of hull and film stiffness, film thickness, ship shape, and engine load in accordance with bearing positions (Dufrane et al., 1983; Saitho, 1983; Choung et al., 2004; Shin and Choe, 2004; Choung et al., 2005; Kuroiwa et al., 2007; Choung and Choe, 2007; Khonsari and Booster, 2008; Takahashi et al., 2009; Vartdal et al., 2009; Shin, 2015; Lee, 2016a, 2016b; Huang et al., 2017; Lee, 2018; Huang et al., 2019; Xie et al., 2019; Lee et al., 2019).

A preferred construction step for performing propulsion shaft alignment is when the vessel is in a dry dock just before the vessel is launched. At this stage, the ship's construction and the shaft assembly are mostly completed. In order to ensure reliable shaft alignment in dry-dock conditions, a more accurate shaft alignment analysis with hull deflection should be considered. After reviewing past studies, it found the lack of comprehensive case studies on hull deformation of ultra-large crude oil carriers. In view of this background, this paper was designed to suggest an appropriate approach to shaft alignment of large tankers by means of theoretical review and actual data analysis.

\section{Approaches adopted}


Fig. 1 outlines the flow of the approach adopted for this research. At the first, global structure analysis are conducted by ship modelling, and next, using data obtained by structural analysis, the method and procedure to perform data conversion to reflect in the shaft alignment calculation are described. Finally, the results of this study are discussed by comparing the analytical results of the above procedure with the experimental results.

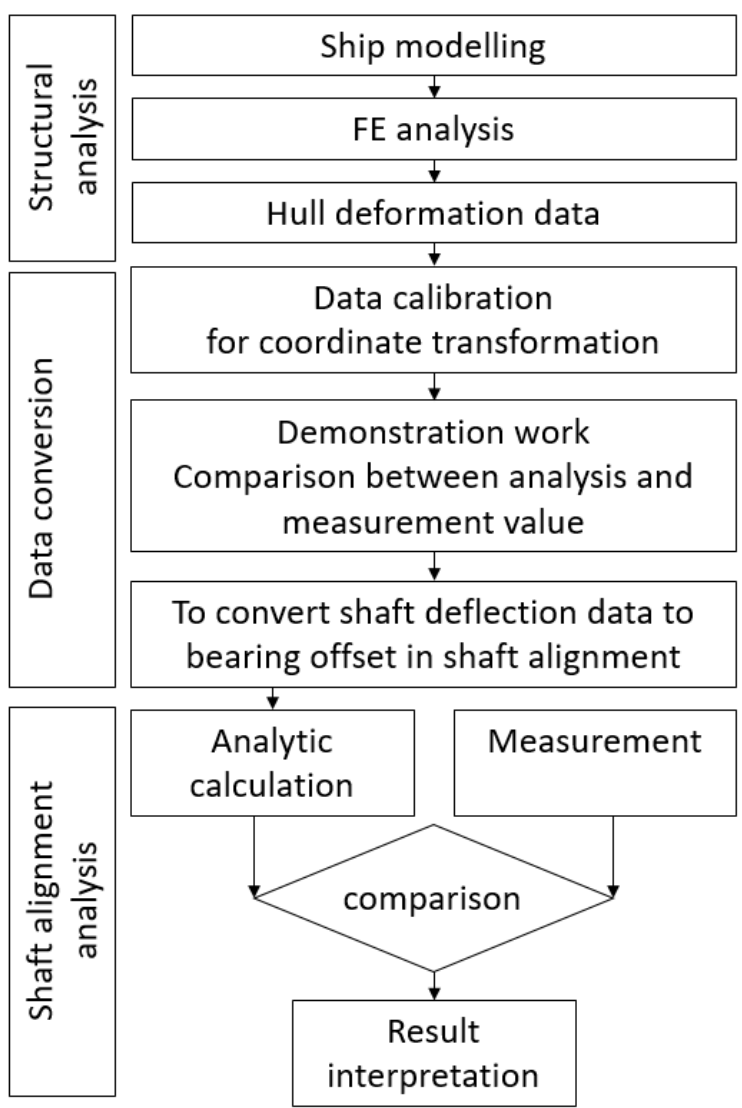

Fig. 1. Study outline.

\subsection{Ship description}

The study presents a database for predicting hull deformation by performing analytical calculations, measurements, and data analysis of 300K DWT (Low Weight Tonnage) Very-Large Crude Oil Carriers (VLCCs). 
For this purpose, the global structure analysis for the whole ship is performed according to the ship draught change with mostly used five scenarios, whereas the shaft alignment analysis is performed based on the hull deformation obtained through the analysis. The global structure analysis is to confirm that the propulsion shafting system complies with the tolerant levels even under the influence of the hull deformation.

In addition, the results of the analytic calculation and jack-up method are compared with each other to verify the reliability of the analysis by cross validating the stability of the shafting system under hull deformation. Table 1 shows the case ship specifications with the shaft system and Fig. 2 illustrates a general ship arrangement and shaft layout.

\section{Table 1}

Specification of ship and shafting system.

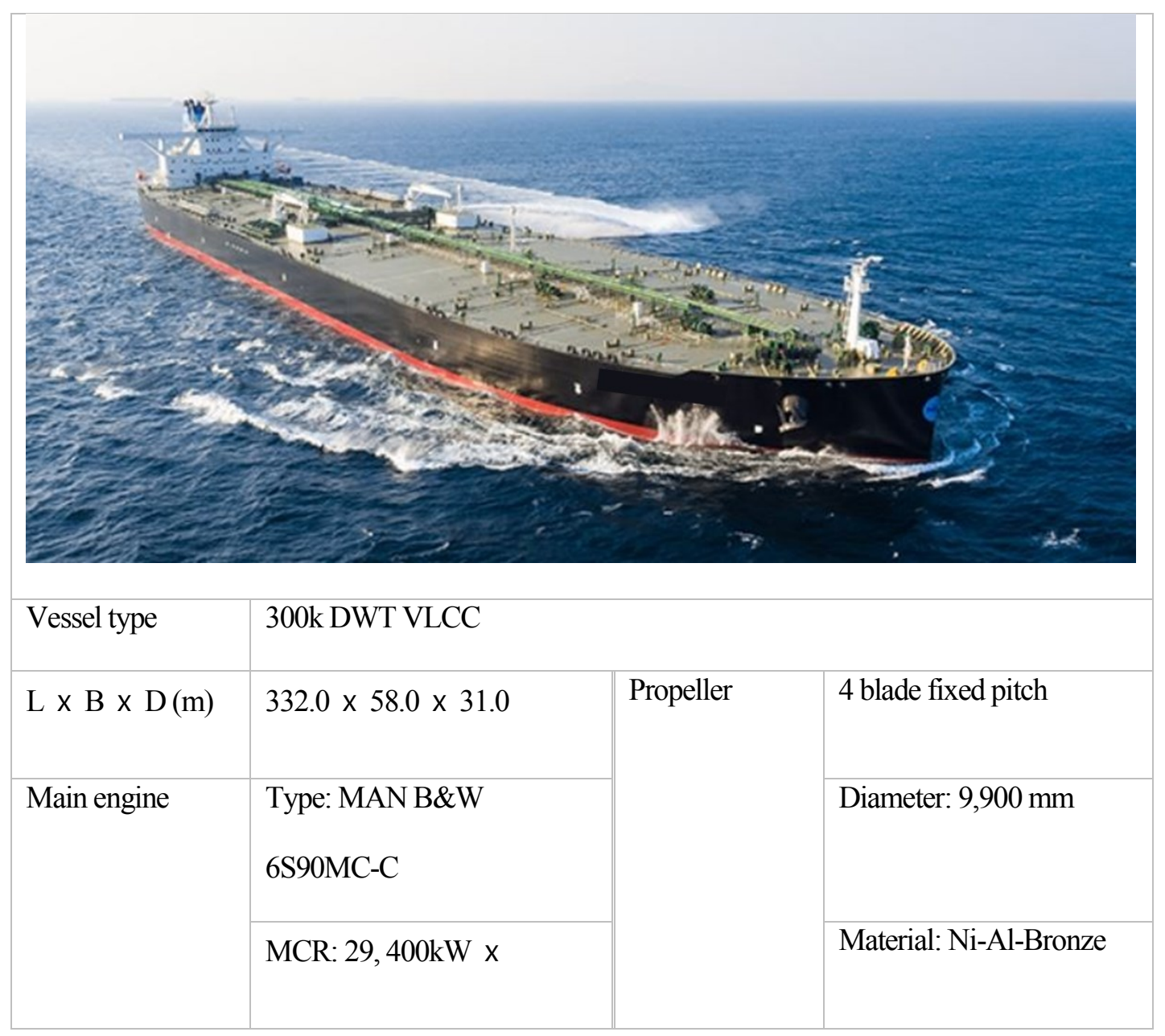




\begin{tabular}{|c|c|c|}
\hline & 76.0rpm & \multirow[b]{2}{*}{ Mass in air: 72.256 ton } \\
\hline & $\begin{array}{l}\text { NCR: } 26,460 \mathrm{~kW} \times 73.4 \\
\text { rpm }\end{array}$ & \\
\hline Shaft & $\begin{array}{l}\text { Material: Forged steel } \\
(\mathrm{SF} 590) \\
\text { Propeller shaft }(\mathrm{L} \times \mathrm{D}) \text { : } \\
10,318 \times 810 \mathrm{~mm} \\
\text { Intermediate shaft }(\mathrm{L} \times \mathrm{D}) \text { : } \\
9,805 \times 725 \mathrm{~mm}\end{array}$ & $\begin{array}{l}\text { Centre of gravity form } \\
\text { AP: } 5,644 \mathrm{~mm}\end{array}$ \\
\hline
\end{tabular}

L: length, B: breadth, D: depth, MCR: maximum continuous rate, NCR: nominal continuous rate, AP:

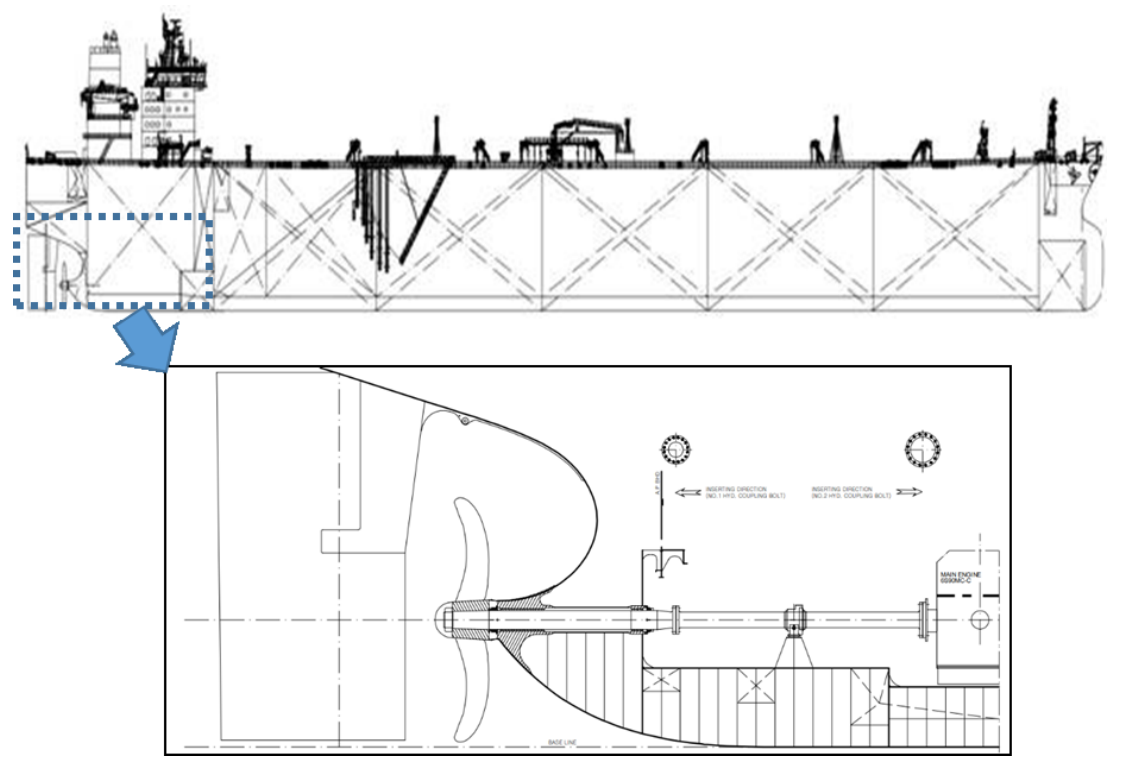

Fig. 2. General arrangement and shaft arrangement of the case ship. 


\subsection{Hull deformation analysis}

\subsubsection{FE model}

FE analysis is not a new approach for investigating ship hull deformation. However, the previous examples are largely limited to small and medium sized vessels, thereby there lack relevant studies for ultra large oil tankers which are often subject to shaft damages. In this context, it has been a strong need to understand the characteristics of hull deformation associated with larger ships and resolve the issues using FE analysis. In order to analyse the hull deformation for this type of vessel, MSC / PATRAN was used as a pre / post program and MSC / NASTRAN (Version 2018.0) was used as a solver. Fig 3 shows the diagrams used for finite element modelling in the analysis.

The two-dimensional shell element (CQUAD4 and CTRIA3) was applied for meshing the 'housing' side whereas the one-dimensional beam element (CBEAM) was used for meshing the 'shaft' side. This mesh generation was determined based on the modelling guide of the classification rules . 


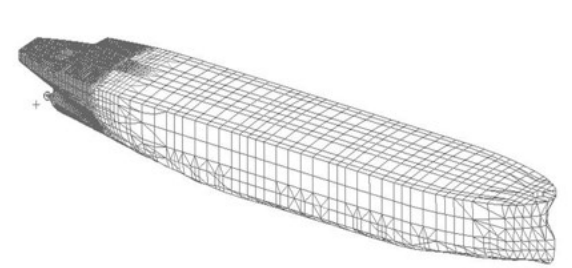

(a) FE model overview of the vessel

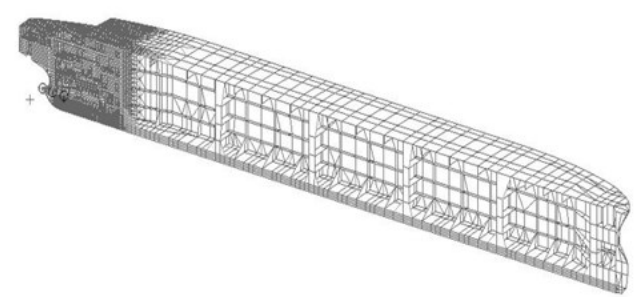

(b) Section view at center line of the vessel

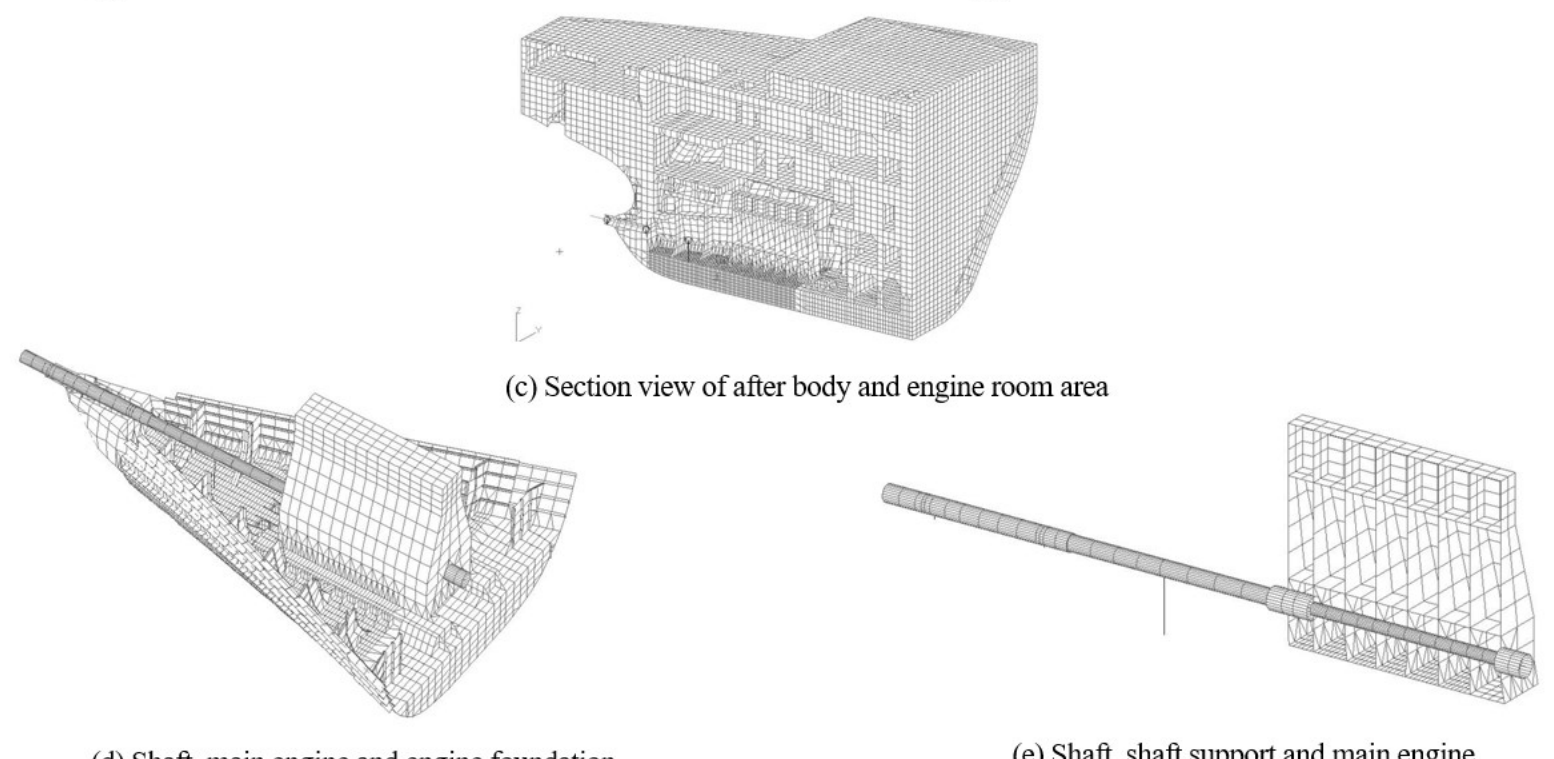

(d) Shaft, main engine and engine foundation

(e) Shaft, shaft support and main engine

Fig. 3. FE models for the case vessel.

Global structure analysis consists of main engine housing structure, crankshaft, propeller shaft and intermediate shafts. The main engine housing was modelled with a shell element and the shafts as a beam element. The propeller shaft was connected to the hull structure using a rigid bar at all the stern tube bearing positions. Similarly, the rigid bars were connected to intermediate shaft and the hull at the intermediate bearing position whereas the crankshaft and the main engine were connected with same nodes. The main engine foundation structure was also connected to the main engine bedplate through the same node. Deckhouse elements, funnels and rudders are not included in the finite element model. Instead, weight was added to the load condition. To more accurately implement the aft body, as shown in Fig. 3 (c), the engine room forward bulkhead of the transom was modelled with a finer mesh with a size of $100 \times 100 \mathrm{~mm}$ in the after body, while using a mesh with a size of $820 \times 820 \mathrm{~mm}$ for the fore body. The governing equation applied for this structural analysis is the linear static equation (e.g [K] $[\mathrm{X}]=[\mathrm{F}])$. Some assumptions were made on the modelling based on general practice: stiffeners with 
'beam elements'; primary members with two-dimensional elements, CQUAD4 and CTRIA3; structural joints with 'perfect bonding'.

\subsubsection{Coordination system, Boundary condition and load condition}

The coordinate system used in the analysis is as follows. The aft perpendicular was set as the origin along the baseline and the bow direction was set to be the positive direction. In addition, the origin reference in the vertical direction was set to the z-axis, the upside was set up as the positive $(+)$. The transverse direction was set to the y-axis, port side was set up as the positive $(+)$.

The boundary conditions applied to the global structure analysis are shown in Fig. 4. The vertical displacement $\left(\mathrm{D}_{z}\right)$ were constrained at the cross point where the baseline and engine room bulkheads as well as the cross point where the forehead bulkhead and the baselines met.

In addition, transverse displacement $\left(\mathrm{D}_{\mathrm{y}}\right)$ was constrained at the cross point where the double bottom tank top, engine room bulkhead and outer hull and engine room bulkheads met, and the upper deck, engine room bulkhead and centreline met.

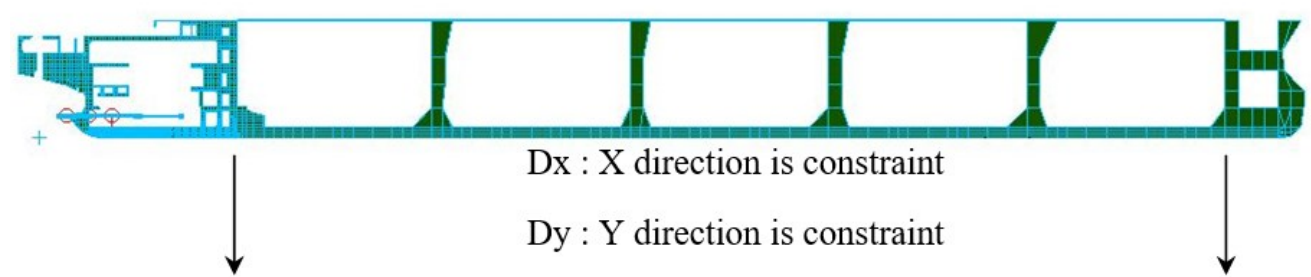

Dy

Dz : Z direction is constraint

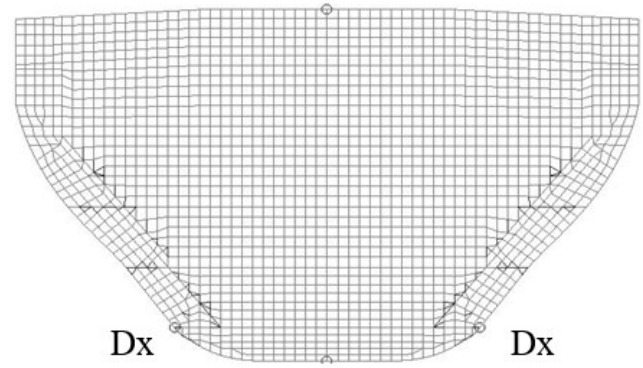

Dz, Dy

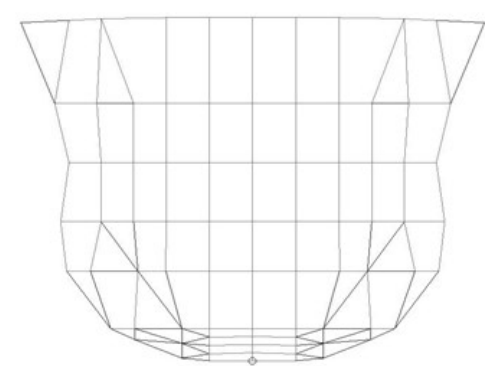

$\mathrm{Dz}$ 
Fig. 4. Boundary condition of the vessel.

As shown in Table 2, based on the draught of the vessel, five credible loading conditions were selected for global structure analysis. The load condition St1 represents the alignment draught condition at quay under which the final alignment occurs. St2 and St3 conditions are ballast draught conditions. St2 describes the aft peak tank full loaded condition whereas St3 is empty of the aft peak tank.

St4 represents the state of the design draught with the aft peak tank full for optimal operation of the vessel, and St5 represents the full draught with the empty state of the after peak tank. With the same concept as in the St 2 and St 3 conditions, the difference between St 4 and St 5 is whether the aft peak tank is loaded.

Table. 2

Loading conditions.

\begin{tabular}{|l|l|l|l|l|}
\hline Condition No. & Condition description & Displacement [ton] & Aft draught [m] & Fwd draught [m] \\
\hline St1 & Alignment draught at quay & $42,765.4$ & 4.118 & 3.525 \\
\hline St2 & Ballast draught APT full & $148,734.1$ & 11.366 & 9.299 \\
\hline St3 & Ballast draught APT empty & $150,656.4$ & 12.046 & 8.949 \\
\hline St4 & Full draught APT full & $320,739.7$ & 20.824 & 20.824 \\
\hline St5 & & & & \\
\hline
\end{tabular}

\subsection{Analysis of Propeller shaft alignment}

This section deals with major considerations for the shaft alignment analysis of the case vessel. 


\subsubsection{Modelling of shaft alignment}

First, modelling work of shafting system should be carried out in advance, as shown in Fig. 5, taking into account the characteristics of the actual complex shaft geometry and layout. At this time, the dimensions, material properties and cross-sectional characteristics of the shafts should be fully considered. If the engine manufacturer provides the information of the engine crankshaft equivalent beam model, it is usually desirable to use it, as shown in Fig. 6. In modelling work, shaft support bearings are usually treated as a single support point with infinite rigid bodies, and it is recommended to ensure the ability to adjust the position of the supports.

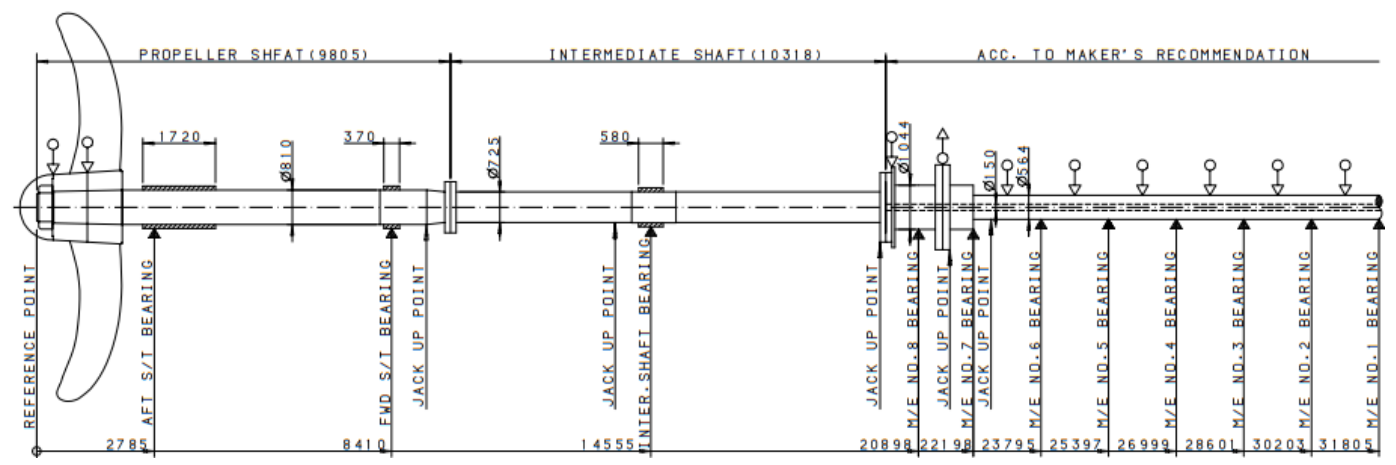

Fig. 5. Modelling of shaft alignment.

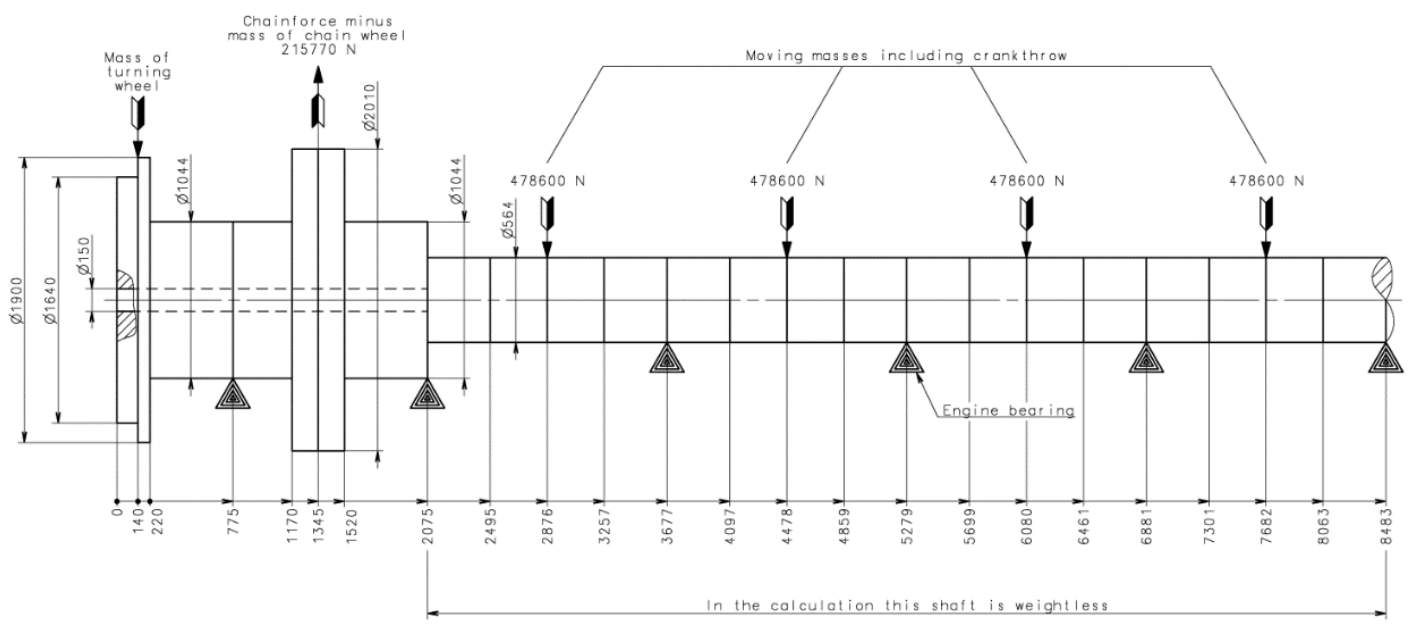

Fig. 6. Modelling data of equivalent crankshaft. 


\subsubsection{Support point of bearings}

Fig.7 shows the after stern tube bearing drawing of the case ship, indicating the location of the support point that was selected to be $\mathrm{D} / 3$ (where $\mathrm{D}$ represents the diameter of the propeller shaft) from the bearing stern end based on the static condition and the support point of other bearings such as the intermediate shaft and main engine bearing was set to the bearing centre for the shaft alignment analysis.

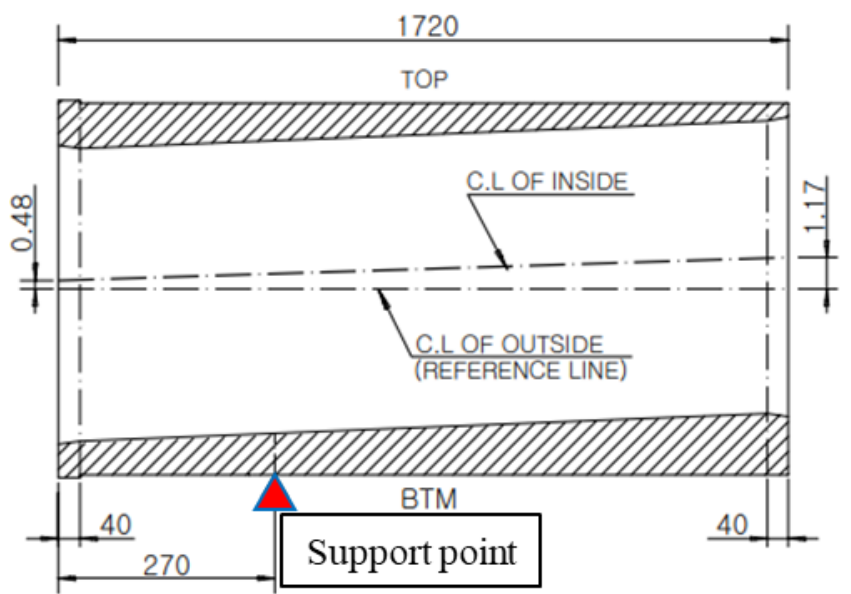

Fig. 7. Drawing of after stern tube bearing and its support point.

\subsubsection{Stiffness of bearings}

Bearing support stiffness can be expressed as the combination of the bearing stiffness, the stiffness of the lubricating oil film formed between the bearing and the shaft, and the structure stiffness supporting the bearing, as presented in equation (1).

$\frac{1}{k_{t}}=\frac{1}{k_{\text {oil }}}+\frac{1}{k_{b}}+\frac{1}{k_{f}}$

Where;

$\mathrm{k}_{\mathrm{t}} \quad$ Total bearing stiffness

$\mathrm{k}_{\text {oil }} \quad$ Oil film stiffness

$\mathrm{k}_{\mathrm{b}} \quad$ Bearing stiffiness 


\section{$\mathrm{k}_{\mathrm{f}} \quad$ Bearing foundation stiffness}

In general, the supporting stiffness of each bearing is recommended to be within the allowable range in Table 3. On the other hand, the supporting stiffness of each support bearing depends on the bearing manufacturer's technology and bearing characteristics; the stiffness of the lubricating oil film is related to the lubricating oil viscosity; structural stiffness is associated with the characteristics of engine room arrangement. Given this, this research adopted a standardised total bearing stiffness value $\left(\mathrm{k}_{\mathrm{t}}\right)$ of $5 \times$ $10^{9} \mathrm{~N} / \mathrm{m}$ which is widely adopted by major Korean Shipyards in accordance with DnVGL rule (DnVGL, 2019). This total stiffness value represents a combination of all stiffnesses associated with oil film, bearing, bearing foundation as described in Table 3.

\section{Table 3}

Typical range for bearing stiffness (Murawski, 2005; Sun, 2019).

\begin{tabular}{|l|l|}
\hline Description & Range $[\mathrm{N} / \mathrm{m}]$ \\
\hline Oil film stiffness( $\left.\mathrm{k}_{\mathrm{oil}}\right)$ & $1.0 \times 10^{8} \sim 5.0 \times 10^{9}$ \\
\hline Bearing stiffness $\left(\mathrm{k}_{\mathrm{b}}\right)$ & $1.0 \times 10^{9} \sim 1.0 \times 10^{10}$ \\
\hline Bearing foundation stiffness $\left(\mathrm{k}_{\mathrm{f}}\right)$ & $1.0 \times 10^{8} \sim 1.0 \times 10^{10}$ \\
\hline Typical range for total bearing stiffness $\left(\mathrm{k}_{\mathrm{t}}\right)$ & $5.0 \times 10^{8} \sim 5.0 \times 10^{9}$ \\
\hline
\end{tabular}

\subsubsection{Material property and external load}

In general, the propeller shaft can be divided into two parts. The first part is where it is exposed to (sea or fresh) water with along the propeller outside the stern structure, immersed in lubricating oil through the stern tube, and the second part is where it is exposed to air in the engine room compartment. 
The intermediate shaft and the crankshaft was assumed to be exposed to ambient condition surrounding the engine room. Therefore, parts submerged in the fluid were to be considered with the buoyancy effect. In addition, the weight of propellers and other parts applied to the shaft system, and the excitation forces when operating the engine (this is commonly referred to as moving mass) were considered as external forces.

On the other hand, the main engine crankshaft equivalent beam information provided by the main engine manufacturer generally considers the self-weight of the crankshaft. Therefore, the density of the crankshaft is treated as " 0 " in order to avoid being applied in duplicate.

Tables 4 and 5 show the material properties and the external forces considered. Based on this, the calculation results are reviewed to estimate the stability of the shaft system by checking whether each support bearing is within the allowable load in Table 6 .

\section{Table 4}

Buoyancy dependent material property of shaft.

\begin{tabular}{|l|c|c|c|c|}
\hline \multicolumn{1}{|c|}{ Condition } & E-MOD & G-MOD & Poisson's & Density \\
& {$[\mathrm{GPa}]$} & {$[\mathrm{GPa}]$} & Ratio $[\mathrm{v}]$ & {$\left[\mathrm{N} / \mathrm{m}^{3}\right]$} \\
\hline \hline Air & 210 & 81 & 0.3 & 76,982 \\
\hline Sea water & 210 & 81 & 0.3 & 66,930 \\
\hline Lub. oil & 210 & 81 & 0.3 & 68,156 \\
\hline Weightless & 210 & 81 & 0.3 & 0 \\
\hline
\end{tabular}

\section{Table 5}

External forces applied on shafting system. 


\begin{tabular}{|l|c|c|}
\hline \multicolumn{1}{|c|}{ Description } & Point load [N] & Remark \\
\hline \hline Propeller cap & 7,384 & 0\% Immersion \\
Propeller & 613,000 & (dry dock condition) \\
\hline Flywheel & 179,800 & \multirow{2}{*}{ According to M/E } \\
Chain force & $-215,770$ & \multirow{2}{*}{ recommendation } \\
\hline Moving masses & 478,600 & \\
& & \\
\hline
\end{tabular}

\section{Table 6}

Permissible load for support bearing respectively on subject vessel.

\begin{tabular}{|c|c|c|c|}
\hline Bearing & $\begin{array}{c}\text { Max. pressure } \\
\text { [MPa] }\end{array}$ & $\begin{array}{c}\text { Projected area of } \\
\text { bearing }\left[\mathrm{mm}^{2}\right]\end{array}$ & $\operatorname{Max} . \operatorname{load}[\mathrm{kN}]$ \\
\hline AFT S/T & 0.8 & $1,395,260$ & 1116 \\
\hline FWD S/T & 0.8 & 300,880 & 240 \\
\hline Inter. shaft & 0.8 & 423,810 & 339 \\
\hline M/E No. 8 & & $\begin{array}{l}\text { Min. 0kN } \\
\text { Max. 958kN }\end{array}$ & \\
\hline $\begin{array}{l}\text { M/E No. } 7 \\
\sim \text { No. } 1\end{array}$ & & $\begin{array}{l}\text { Min. } 48 \mathrm{kN} \\
\text { Max. } 958 \mathrm{kN}\end{array}$ & \\
\hline
\end{tabular}

\section{Results and discussion}

The proposed approach discussed in the previous section was applied to the case study. This section deals with the analysis results. 


\subsection{Hull deformation analysis}

First, the results of the hull deformation according to the global structural analysis are shown in Fig. 8 (St1 condition) and Fig. 9 (St5 condition) which shows the greatest level of hull deformation due to the draught variation. To improve visuality, the overall scale of the hull was determined at 600: 1 , and the after body scale was at 60: 1 .
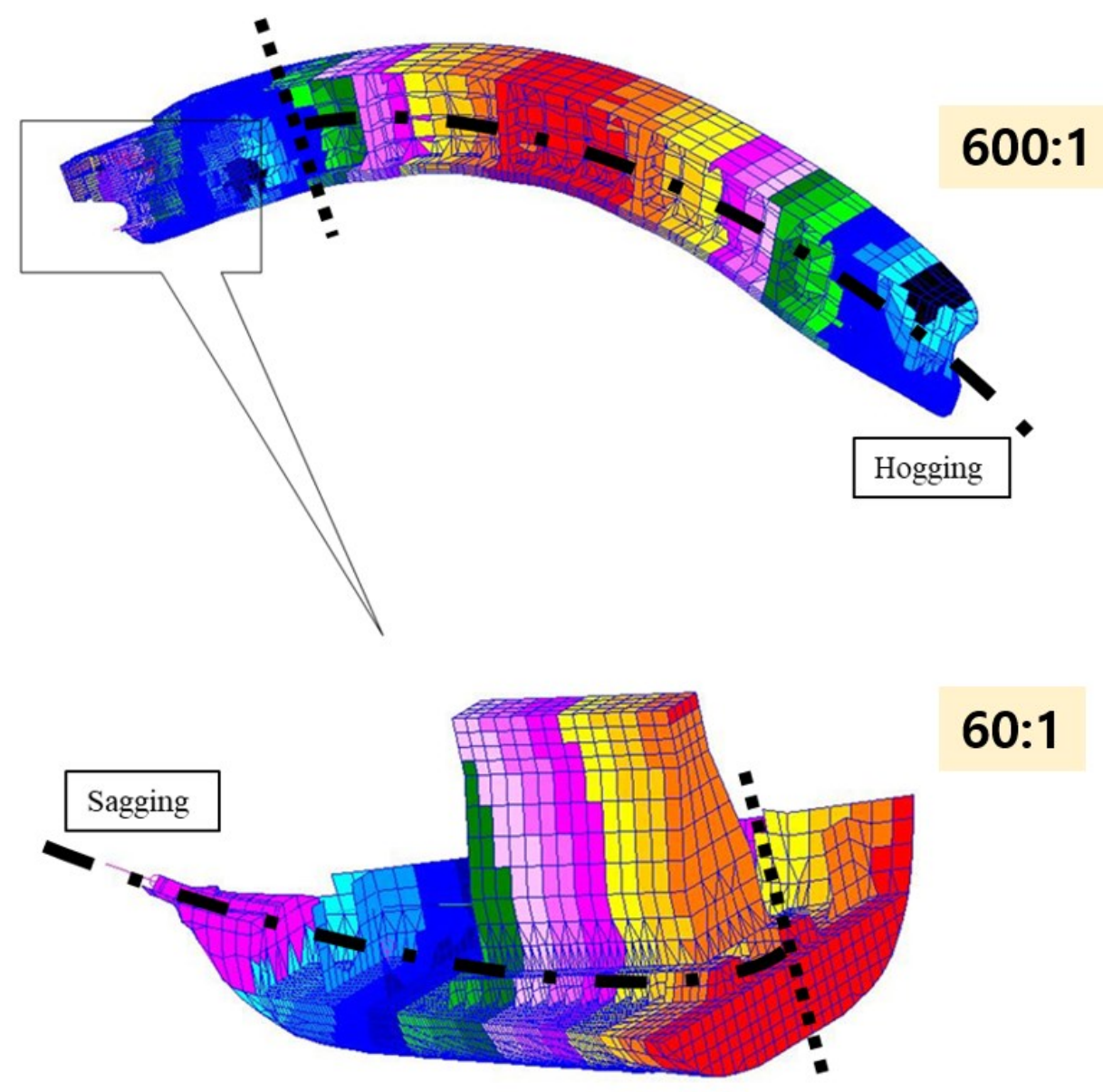

$60: 1$

Fig. 8. Hull deformation result at St1 (Alignment draught at quay) condition.

In Fig. 8 of the alignment draught condition St1, the hull deformation has a pattern in which the hull is deformed in the hogging direction whereas the engine room is deformed in the sagging direction. 


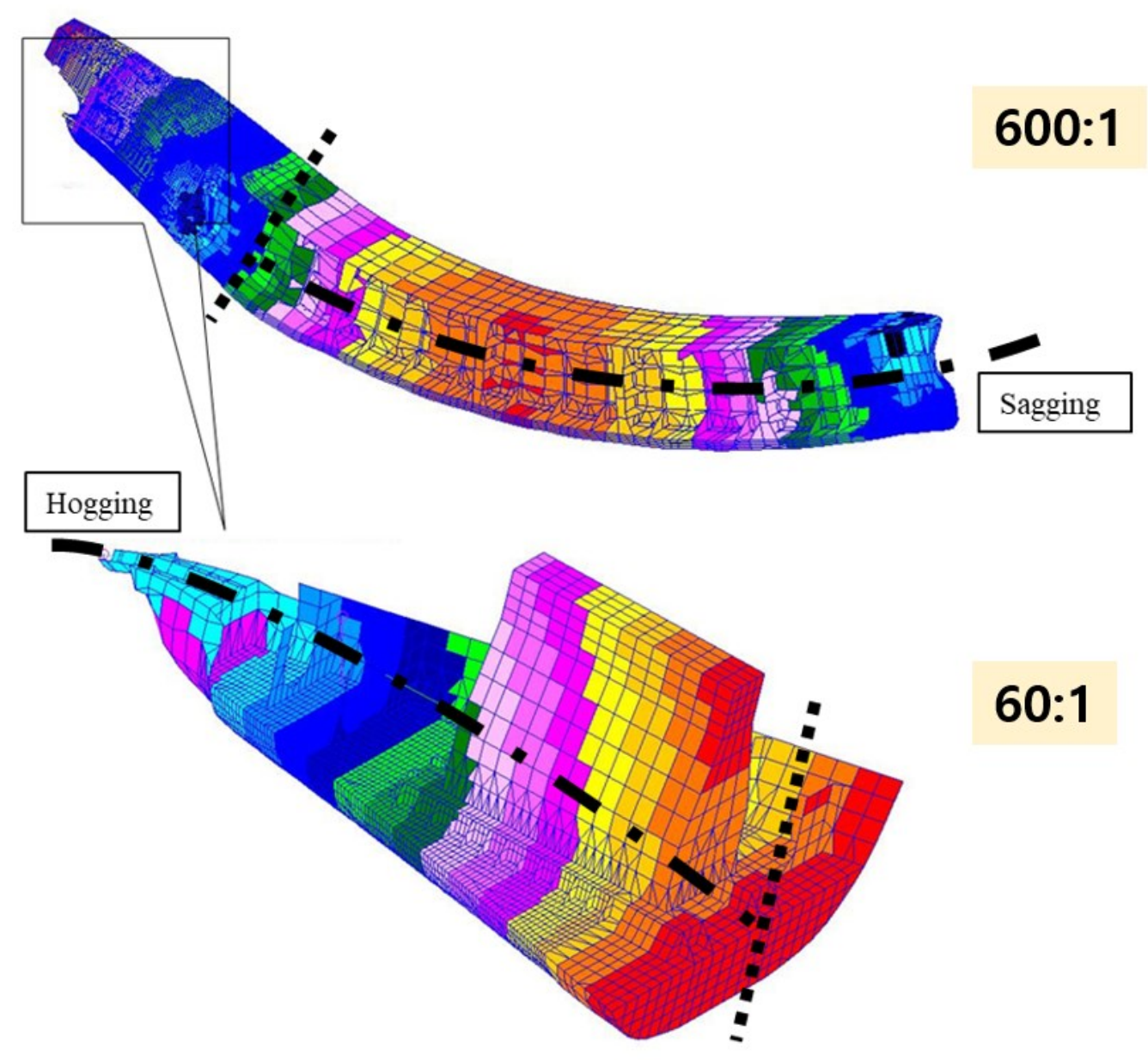

Fig. 9. Hull deformation at St5 (Full draught APT empty) condition.

On the other hand, the opposite trend is found in the full draught condition (St5) given in Fig. 9 where the hull is deformed in the sagging direction whereas the engine compartment is deformed in the hogging direction.

Unlike other linear cases, this analysis can confirm that the effects of hull deformation are imposed on the shaft system in the opposite format. 
Fig. 10 illustrates the hull deformation obtained from FE analysis for each condition and clearly indicates that the hull is deformed to the hogging state under the ballast conditions, St1, St2, St3, and sagging under the cargo loading conditions, St4, St5.
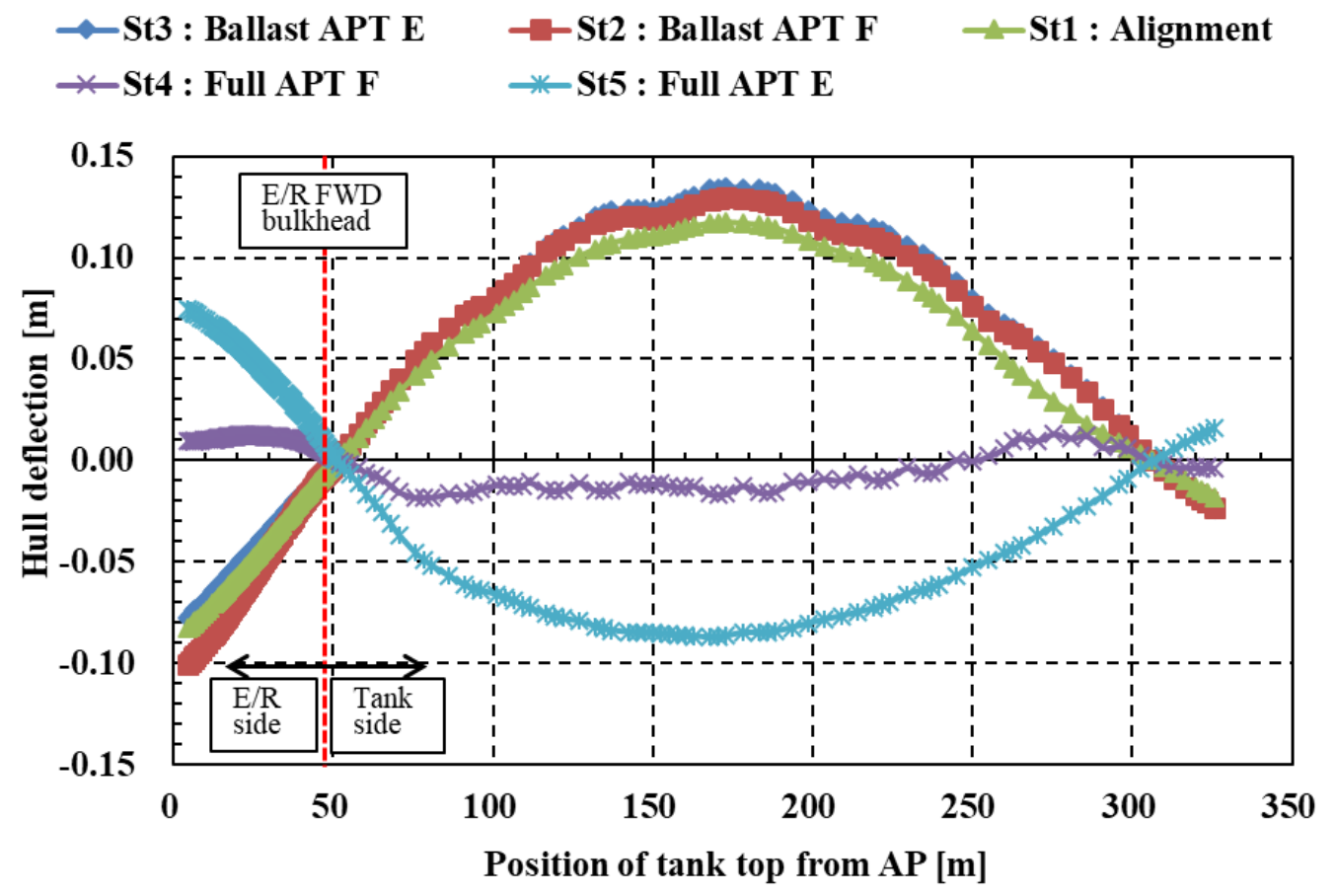

Fig. 10. Hull deformation state at each condition obtained from FE analysis.

To use the hull deformation data obtained from the structure analysis for the shaft alignment analysis in the next step, it needs to perform additional data corrections to rotate the coordinates to create an imaginary straight line. It becomes a standard line connecting the bow and stern bearing offsets at both ends of the stern tube. 
Meanwhile, the purpose of data corrections may need to be discussed. First, the housing of the stern tube bearing, intermediate shaft bearing, and main engine bearing supporting the shaft are integrated with the hull so that these parts (to the pedestal below the support bearing welded to the hull, not to the shaft centre) can be in constrained conditions in the analysis. However, the shaft is not in a constrained condition with the bearings and it is supported by journal bearing and oil film during rotation to transmit the rotational force of the engine to the propeller. Therefore, it is not easy to implement the confined state in FE analysis. For this reason, the deflection data of the hull is first obtained through FE analysis, and through data correction, the deflection data at each position of the support bearing is added to the shaft deflection at the corresponding position.

This approach is presently applied in large shipyards in South Korea and recognised by the classification societies due to the fact that such a coordinate transformation method is useful not only for calculating the shaft alignment and but also for understanding the analysis results. Fig. 11 shows the transformation coordinate system for rotation using Equation (2).

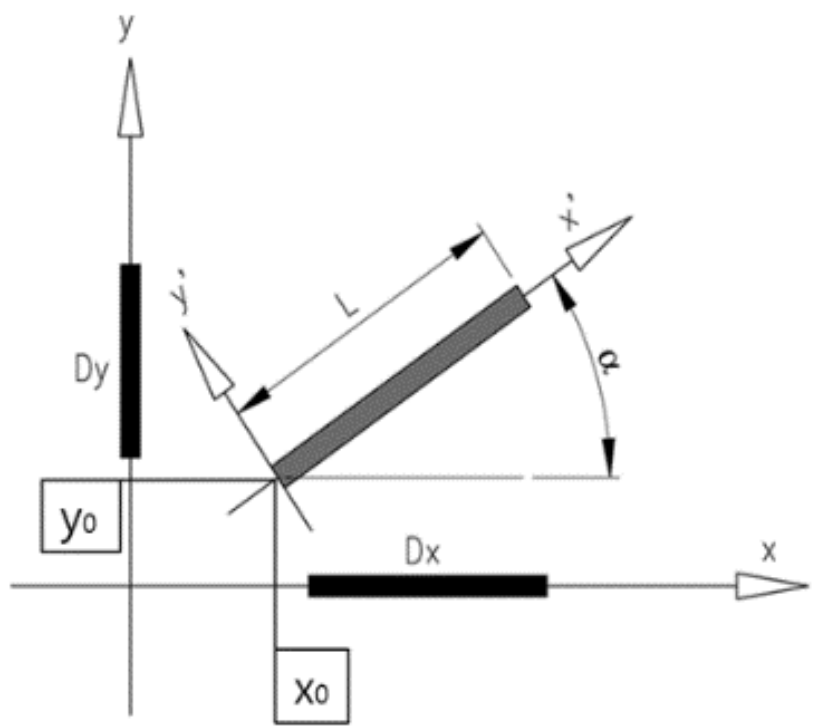

Fig. 11. Coordinate system of transformation. 
$\left\{\begin{array}{l}x^{\prime} \\ y^{\prime}\end{array}\right\}=\left[\begin{array}{cc}\cos \alpha & \sin \alpha \\ -\sin \alpha & \cos \alpha\end{array}\right]\left\{\begin{array}{l}x-x_{0} \\ y-y_{0}\end{array}\right\}$

Where $\left\{\begin{array}{l}x \\ y\end{array}\right\}$ is the point coordinate of the coordinate system before conversion, and $\left\{\begin{array}{l}x^{\prime} \\ y^{\prime}\end{array}\right\}$ is the point coordinate system converted by compensating with the original coordinate $\left\{\begin{array}{l}x_{0} \\ y_{0}\end{array}\right\}$ so that the y axis become ' 0 ' after the coordinate transformation. Also, $\left[\begin{array}{cc}\cos \alpha & \sin \alpha \\ -\sin \alpha & \cos \alpha\end{array}\right]$ is the coordinate transformation matrix.

The results of the coordinate transformation (relative shaft deflection) from hull deflection data for the engine room part are presented in Fig. 12 and Table 7.

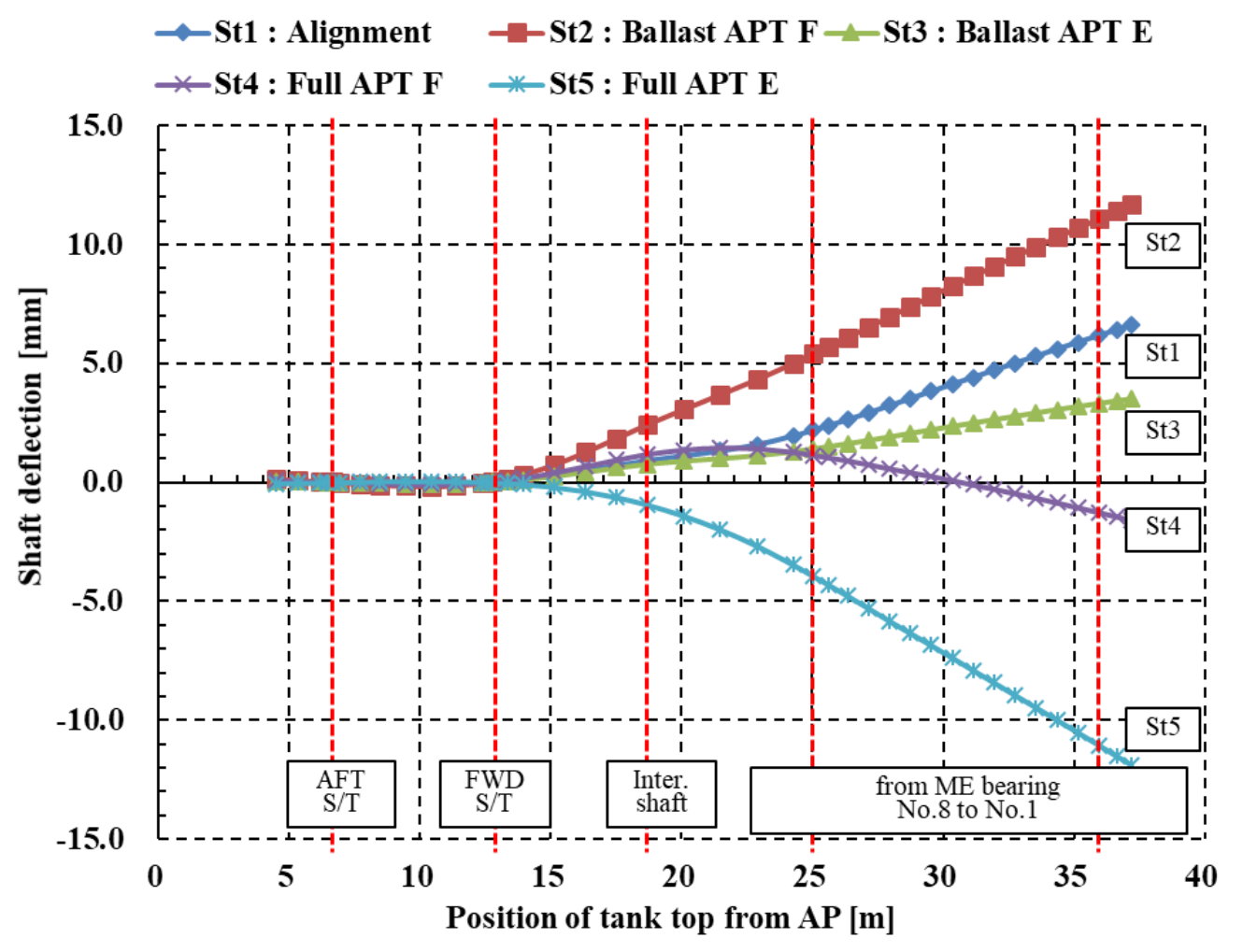

Fig. 12. Relative shaft deflection at each condition obtained by transformation. 


\section{Table 7}

Relative shaft deflection at supporting point of bearings respectively.

\begin{tabular}{|c|c|c|c|c|c|}
\hline Bearing & $\begin{array}{c}\text { St1 } \\
{[\mathrm{mm}]}\end{array}$ & $\begin{array}{c}\mathrm{St} 2 \\
{[\mathrm{~mm}]}\end{array}$ & $\begin{array}{c}\mathrm{St} 3 \\
{[\mathrm{~mm}]}\end{array}$ & $\begin{array}{c}\text { St4 } \\
{[\mathrm{mm}]}\end{array}$ & $\begin{array}{c}\mathrm{St} 5 \\
{[\mathrm{~mm}]}\end{array}$ \\
\hline AFT S/T & 0.00 & 0.00 & 0.00 & 0.00 & 0.00 \\
\hline FWD S/T & 0.00 & 0.00 & 0.00 & 0.00 & 0.00 \\
\hline Inter. shaft & 0.91 & 2.43 & 0.77 & 1.17 & -0.94 \\
\hline M/E No.8 & 2.20 & 5.41 & 1.42 & 1.14 & -3.94 \\
\hline M/E No.7 & 2.64 & 6.10 & 1.63 & 0.92 & -4.76 \\
\hline M/E No.6 & 3.22 & 6.96 & 1.92 & 0.58 & -5.82 \\
\hline M/E No.5 & 3.83 & 7.84 & 2.22 & 0.27 & -6.85 \\
\hline M/E No.4 & 4.42 & 8.68 & 2.50 & -0.09 & -7.90 \\
\hline M/E No.3 & 5.01 & 9.50 & 2.78 & -0.45 & -8.95 \\
\hline M/E No.2 & 5.60 & 10.31 & 3.06 & -0.84 & -9.99 \\
\hline M/E No.1 & 6.18 & 11.10 & 3.32 & -1.25 & -11.05 \\
\hline
\end{tabular}

The final bearing offset value for the shaft alignment calculation considering the hull deformation is determined from the process with which the relative shaft deflection data in Table 7 is reflected in the bearing offset values used in the shaft alignment design.

The results shown in Table 8 and Fig. 13, clearly show the effect of hull deformation on the shaft alignment. As the ship draught moves from light loads (St2 \& St3) to full loads (St4 \& St5), the shaft system is shifted from right upward to right downward compared to the design conditions (cold/hot). 


\section{Table 8}

Bearing offsets derived from the effect of hull deformations.

\begin{tabular}{|c|c|c|c|c|c|c|c|}
\hline \multirow{2}{*}{ Bearing } & \multicolumn{2}{|c|}{ Design[mm] } & \multirow{2}{*}{$\begin{array}{c}\text { St1 } \\
{[\mathrm{mm}]}\end{array}$} & \multirow{2}{*}{$\begin{array}{c}\mathrm{St} 2 \\
{[\mathrm{~mm}]}\end{array}$} & \multirow{2}{*}{$\begin{array}{r}\mathrm{St} 3 \\
{[\mathrm{~mm}]}\end{array}$} & \multirow{2}{*}{$\begin{array}{r}\mathrm{St} 4 \\
{[\mathrm{~mm}]}\end{array}$} & \multirow{2}{*}{$\begin{array}{c}\mathrm{St} 5 \\
{[\mathrm{~mm}]}\end{array}$} \\
\hline & Cold & Hot & & & & & \\
\hline AFT S/T & 0.00 & 0.00 & 0.00 & 0.00 & 0.00 & 0.00 & 0.00 \\
\hline FWD S/T & 0.00 & 0.00 & 0.00 & 0.00 & 0.00 & 0.00 & 0.00 \\
\hline Inter. shaft & -2.50 & -2.50 & -1.59 & -0.07 & -1.73 & -1.33 & -3.44 \\
\hline M/E No. 8 & -4.70 & -4.31 & -2.50 & 1.10 & -2.89 & -3.17 & -8.25 \\
\hline M/E No. 7 & -4.70 & -4.31 & -2.06 & 1.79 & -2.68 & -3.39 & -9.07 \\
\hline M/E No. 6 & -4.70 & -4.31 & -1.48 & 2.65 & -2.39 & -3.73 & -10.13 \\
\hline M/E No. 5 & -4.70 & -4.31 & -0.87 & 3.53 & -2.09 & -4.04 & -11.16 \\
\hline M/E No. 4 & -4.70 & -4.31 & -0.28 & 4.37 & -1.81 & -4.40 & -12.21 \\
\hline M/E No. 3 & -4.70 & -4.31 & 0.31 & 5.19 & -1.53 & -4.76 & -13.26 \\
\hline M/E No. 2 & -4.70 & -4.31 & 0.90 & 6.00 & -1.25 & -5.15 & -14.30 \\
\hline M/E No. 1 & -4.70 & -4.31 & 1.48 & 6.79 & -0.99 & -5.56 & -15.36 \\
\hline
\end{tabular}




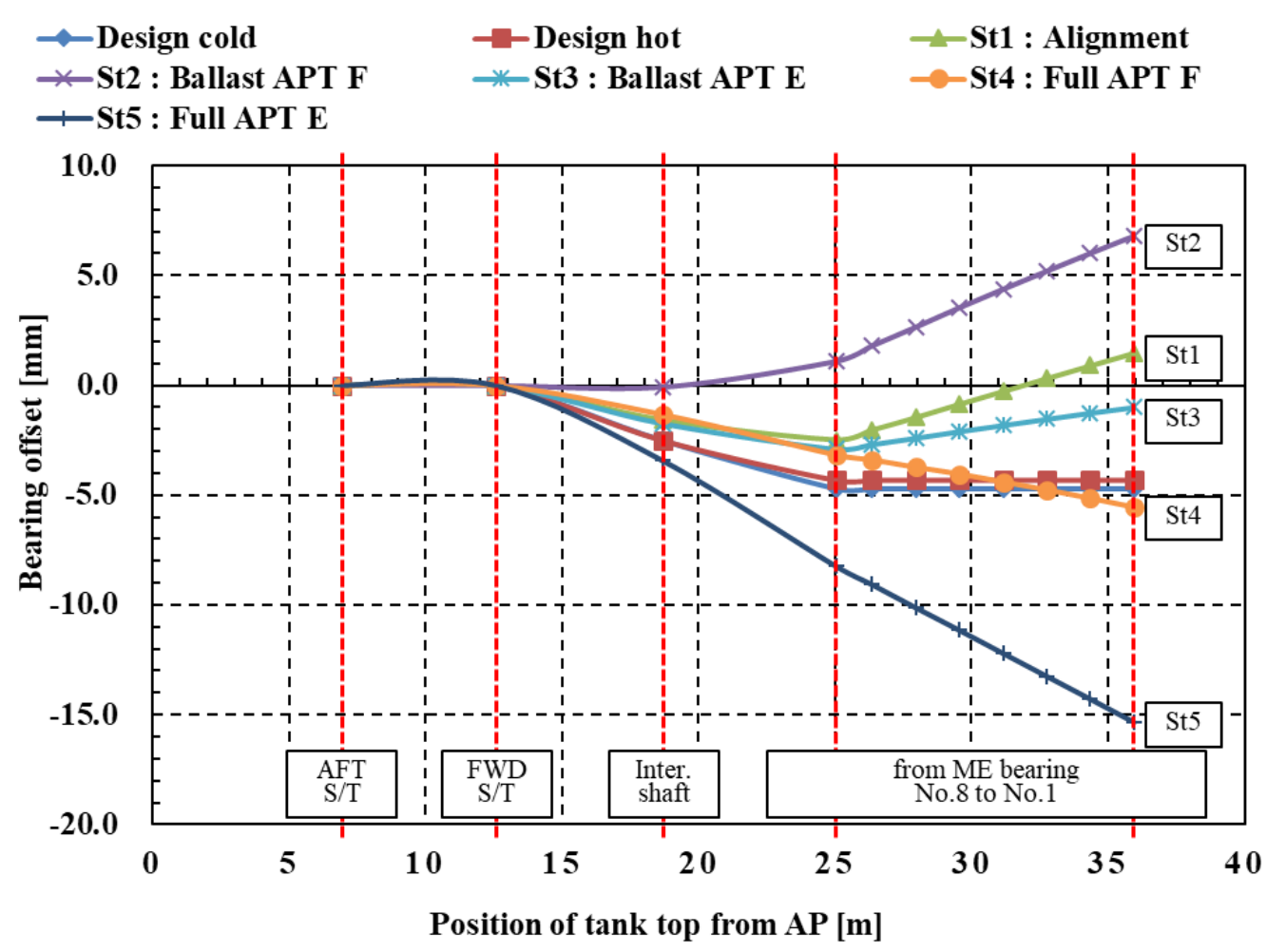

Fig. 13. Draught dependent shaft deflection curves.

\subsection{Shaft alignment analysis and measurement comparison}

This section shows the results of the comparative calculations between the analysis values of the shaft alignment with the measured values. Table 9 as well as Fig. 14 and Fig. 15 show the result of comparing the bearing reaction force calculated with the hull deformation under each draught condition with the design value. 
Table 9

Bearing reaction forces at each condition reflected hull deformation compared with design condition not reflected hull deflection.

\begin{tabular}{|c|c|c|c|c|c|c|c|c|c|}
\hline \multirow{2}{*}{ Bearing } & \multirow{2}{*}{$\begin{array}{c}\text { Position } \\
{[\mathrm{m}]}\end{array}$} & \multicolumn{2}{|c|}{$\operatorname{Design}[\mathrm{kN}]$} & \multirow{2}{*}{$\begin{array}{c}\mathrm{St} 1[\mathrm{kN}] \\
\text { Draught }: 4.1 \mathrm{~m}\end{array}$} & \multirow{2}{*}{$\begin{array}{c}\mathrm{St} 2[\mathrm{kN}] \\
\text { Draught }: 11.4 \mathrm{~m}\end{array}$} & \multirow{2}{*}{$\begin{array}{c}\mathrm{St} 3[\mathrm{kN}] \\
\text { Draught }: 12.1 \mathrm{~m}\end{array}$} & \multirow{2}{*}{$\begin{array}{c}\mathrm{St} 4[\mathrm{kN}] \\
\text { Draught }: 20.8 \mathrm{~m}\end{array}$} & \multirow{2}{*}{$\begin{array}{c}\mathrm{St} 5[\mathrm{kN}] \\
\text { Draught }: 22.5 \mathrm{~m}\end{array}$} & \multirow{2}{*}{$\begin{array}{c}\text { Max. } \\
\text { Per. load } \\
{[\mathrm{kN}]}\end{array}$} \\
\hline & & Cold & Hot & & & & & & \\
\hline $\begin{array}{l}\text { AFT } \\
\text { S/T }\end{array}$ & 6.93 & 1070 & 936 & 1047 & 1000 & 952 & 970 & 906 & 1116 \\
\hline $\begin{array}{c}\text { FWD } \\
\text { S/T }\end{array}$ & 12.56 & 112 & 178 & 69 & 25 & 115 & 65 & 195 & 240 \\
\hline $\begin{array}{l}\text { Inter. } \\
\text { shaft }\end{array}$ & 18.70 & 209 & 141 & 271 & 251 & 209 & 241 & 127 & 339 \\
\hline $\begin{array}{c}\mathrm{M} / \mathrm{E} \\
\text { No. } 8\end{array}$ & 25.04 & 32 & 198 & 28 & 232 & 235 & 413 & 505 & $\begin{array}{c}\text { Min. } \\
0 \\
\text { Max. } \\
958\end{array}$ \\
\hline $\begin{array}{c}\mathrm{M} / \mathrm{E} \\
\text { No. } 7\end{array}$ & 26.34 & 426 & 299 & 343 & 205 & 201 & 112 & 55 & \\
\hline $\begin{array}{c}\mathrm{M} / \mathrm{E} \\
\text { No. } 6\end{array}$ & 27.95 & 487 & 487 & 525 & 498 & 497 & 415 & 409 & \\
\hline $\begin{array}{c}\mathrm{M} / \mathrm{E} \\
\text { No. } 5\end{array}$ & 29.55 & 480 & 480 & 534 & 541 & 542 & 571 & 562 & Min. \\
\hline $\begin{array}{c}\mathrm{M} / \mathrm{E} \\
\text { No. } 4\end{array}$ & 31.15 & 476 & 476 & 451 & 450 & 451 & 441 & 444 & $\begin{array}{c}48 \\
\text { Max. }\end{array}$ \\
\hline $\begin{array}{c}\mathrm{M} / \mathrm{E} \\
\text { No. } 3\end{array}$ & 32.75 & 503 & 503 & 476 & 478 & 476 & 479 & 473 & 958 \\
\hline $\begin{array}{c}\mathrm{M} / \mathrm{E} \\
\text { No. } 2\end{array}$ & 34.35 & 375 & 375 & 398 & 399 & 399 & 398 & 401 & \\
\hline $\begin{array}{c}\mathrm{M} / \mathrm{E} \\
\text { No. } 1\end{array}$ & 35.96 & 536 & 536 & 532 & 530 & 532 & 531 & 532 & \\
\hline
\end{tabular}




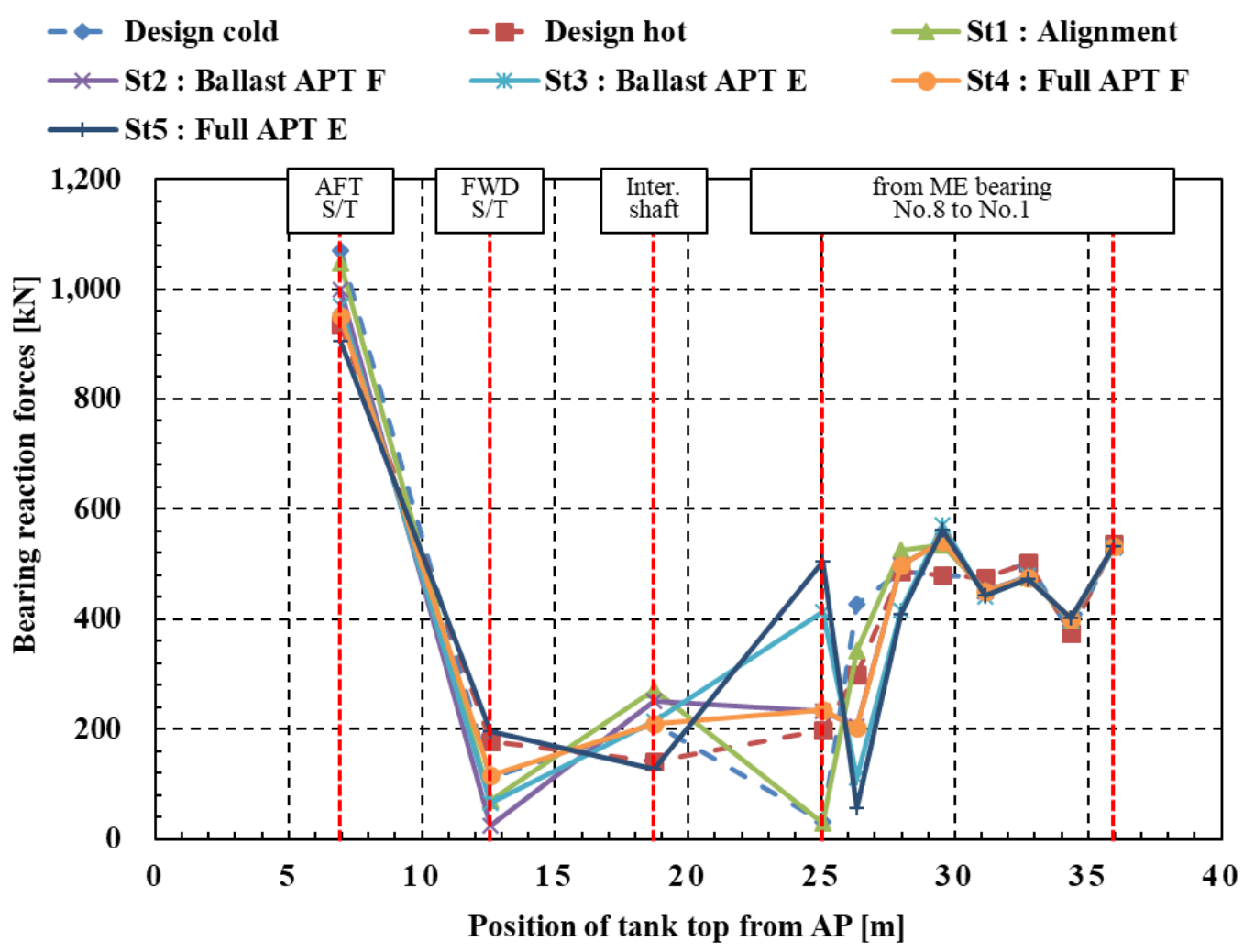

Fig. 14. Bearing reaction forces at each condition reflected hull deflection compared with design condition not reflected hull deflection.

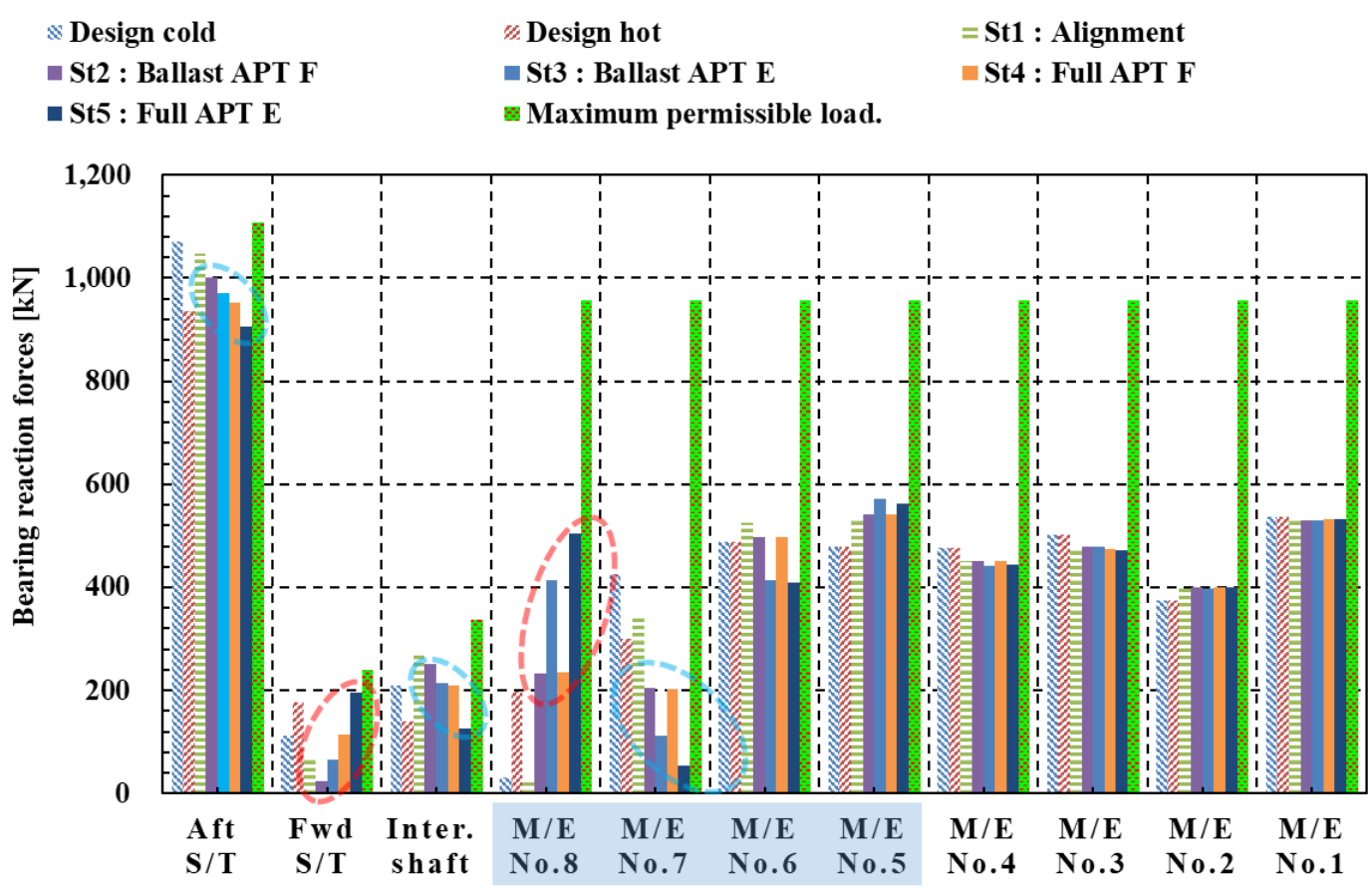


Fig. 15. Bearing reaction forces at each condition reflected hull deflection compared with design condition not reflected hull deflection.

The analysis shows that the reaction forces of the shaft bearings under all conditions are properly loaded within the maximum permissible load. In addition, as the draught increased from St2 to St5, the following remarkable characteristics of reaction force change appeared.

1) After stern tube bearings, the intermediate shaft bearings and the M/E No. 7 bearings showed a decreasing pattern in reaction force, whereas the forward stern tube bearings and the $\mathrm{M} / \mathrm{E}$ No. 8 bearings showed a tendency to increase reaction force.

2) The reaction force of M/E No. $4 \sim$ No.1 bearing was not significantly influenced by the draught change, which is consistent with previous studies.

3) M/E No. $8 \sim$ No 5 bearings showed significant variation in reaction force depending on the ballast loading of the aft peak tank.

Large deviations were observed in No. 6 to No. 8 M/E bearings. This phenomenon can be understood if considering the concept of Reaction Influence Number (RIN): the influence coefficients for $\mathrm{M} / \mathrm{E}$ bearings Nos $6-8$ are $3,087 \mathrm{kN} / \mathrm{mm}, 5,866 \mathrm{kN} / \mathrm{mm}$ and 3,683 kN/mm, respectively, which are relatively high compared to other bearings.

Here, the influence coefficient of bearing reaction force refers to the change in reaction force of other bearings that can appear on the condition; when the support point position of each bearing is on the same horizontal plane and one of their support points is changed to be raised or lowered by a unit height (usually $1 \mathrm{~mm}$ ). This height is mainly determined by the stiffness of the shaft and the distance between the bearings. The smaller the bearing influence coefficient, the smaller the reaction force change. The opposite is also true.

Therefore, as shown in Fig. 16, when the one bearing offset is arbitrarily adjusted by $1 \mathrm{~mm}$, the influence of the main engine bearing offset variation is much larger than that of the stern tube bearing and the intermediate shaft bearing. 
This means that the reaction force of the main engine bearing fluctuates very sensitively even with a slight offset change. In addition, such offset variations are considered margin errors that can usually occur during shipbuilding operations. These are related to the sag tolerances of the main engine bed plate, the deviation among the centre of main bearings, and the margin when the engine is installed at an angle of inclination than the design. Given this, operator attention is required to ensure that errors are not to be cumulative at each process step.

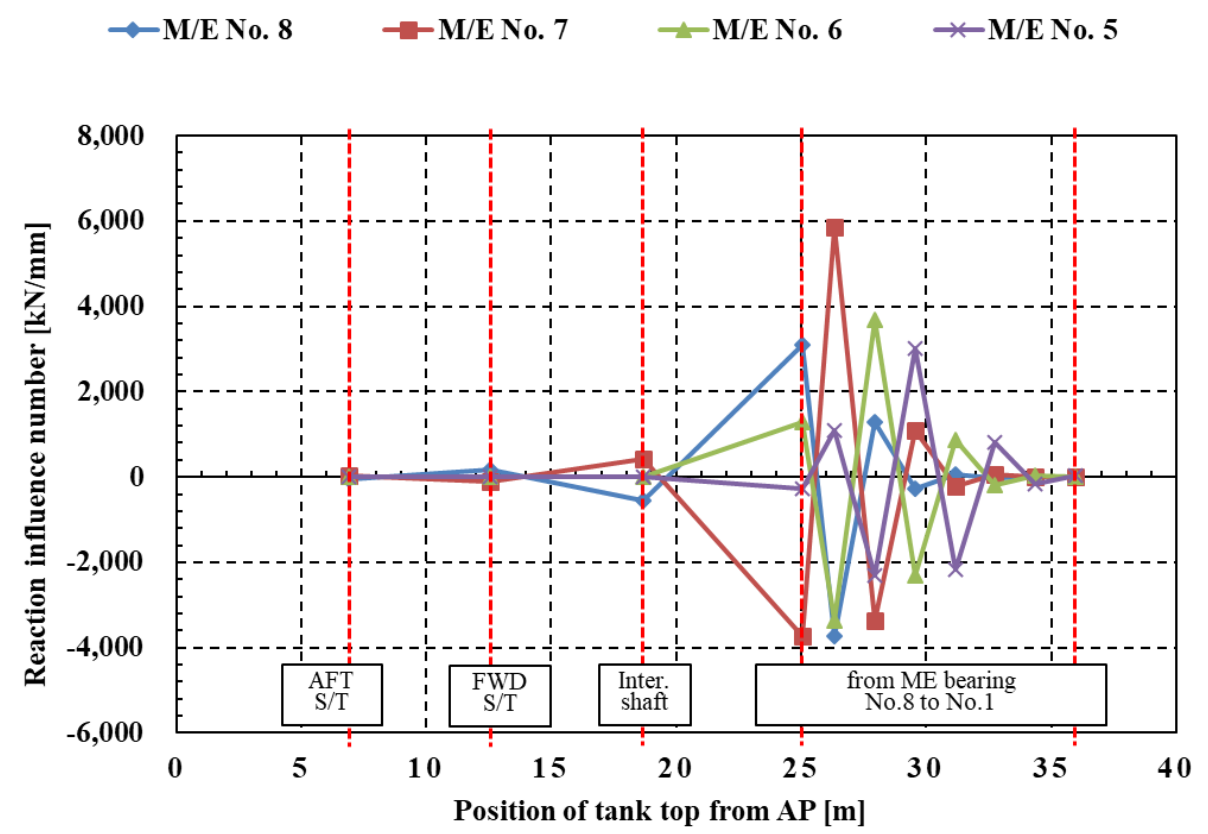

Fig. 16. Offset dependent RIN when bearing is moved by $1 \mathrm{~mm}$ respectively.

As described above, it was examined whether the change of reaction force of the shaft support bearing within the allowable value even under the influence of the hull deformation. In addition, to confirm the reliability of the analysis, the analytical method and the jack-up method, which are typical for the St1, St3, and St4 conditions, are compared to each other. Results are shown in Table 10 and Figs 17.

\section{Table 10}

Correlation between analytical and experimental methods under representative three (3) draught condition. 


\begin{tabular}{|c|c|c|c|c|c|c|c|}
\hline $\begin{array}{l}\text { Draught } \\
\text { condition }\end{array}$ & Method & $\begin{array}{c}\text { AFT S/T } \\
{[\mathrm{kN}]}\end{array}$ & $\begin{array}{c}\text { FWD } \\
\mathrm{S} / \mathrm{T}[\mathrm{kN}] \\
1)\end{array}$ & $\begin{array}{c}\text { Inter. } \\
\text { Shaft } \\
{[\mathrm{kN}]^{2)}}\end{array}$ & $\begin{array}{c}\mathrm{M} / \mathrm{E} \\
\mathrm{No} .8 \\
{[\mathrm{kN}]^{3)}}\end{array}$ & $\begin{array}{c}\mathrm{M} / \mathrm{E} \\
\mathrm{No.7} \\
{[\mathrm{kN}]^{3)}}\end{array}$ & $\begin{array}{c}\mathrm{M} / \mathrm{E} \\
\text { No.6 } \\
{[\mathrm{kN}]^{3)}}\end{array}$ \\
\hline \multirow{3}{*}{ St1 } & Calculated & 1047 & 69 & 271 & 28 & 343 & 525 \\
\hline & Jack up measured & - & 89 & 279 & 4 & 294 & 488 \\
\hline & Manufacturer's limit & 1116 & 240 & 339 & $\begin{array}{c}\text { Min } 0 \\
\text { Max } 958\end{array}$ & $\begin{array}{c}\text { Min } 48 \\
\text { Max } 958\end{array}$ & $\begin{array}{c}\text { Min } 48 \\
\text { Max } 958\end{array}$ \\
\hline \multirow{3}{*}{ St3 } & Calculated & 952 & 115 & 209 & 235 & 201 & 497 \\
\hline & Jack up measured & - & 142 & 224 & 245 & 128 & 448 \\
\hline & Manufacturer's limit & 1116 & 240 & 339 & $\begin{array}{c}\text { Min } 0 \\
\text { Max } 958\end{array}$ & $\begin{array}{c}\text { Min } 48 \\
\text { Max } 958\end{array}$ & $\begin{array}{c}\text { Min } 48 \\
\text { Max } 958\end{array}$ \\
\hline \multirow{3}{*}{ St4 } & Calculated & 970 & 65 & 214 & 413 & 112 & 414 \\
\hline & Jack up measured & - & 125 & 247 & 300 & 69 & 440 \\
\hline & Manufacturer's limit & 1116 & 240 & 339 & $\begin{array}{c}\text { Min } 0 \\
\text { Max } 958\end{array}$ & $\begin{array}{c}\text { Min } 48 \\
\text { Max } 958\end{array}$ & $\begin{array}{c}\text { Min } 48 \\
\text { Max } 958\end{array}$ \\
\hline
\end{tabular}

1), 3) Jack-up measured bearing reaction are within the manufacturer's limit

2) Jack-up tolerance is $\pm 20 \%$ at Inter. Shaft bearing 
$\rightarrow$ Calculated(St4)

*-Maximum permissible load.

Calculated(St1)

Measured with jack-up(St1)
Measured with jack-up(St4)

*-Minimum permissible load

Calculated(St3)

Measured with jack-up(St3)

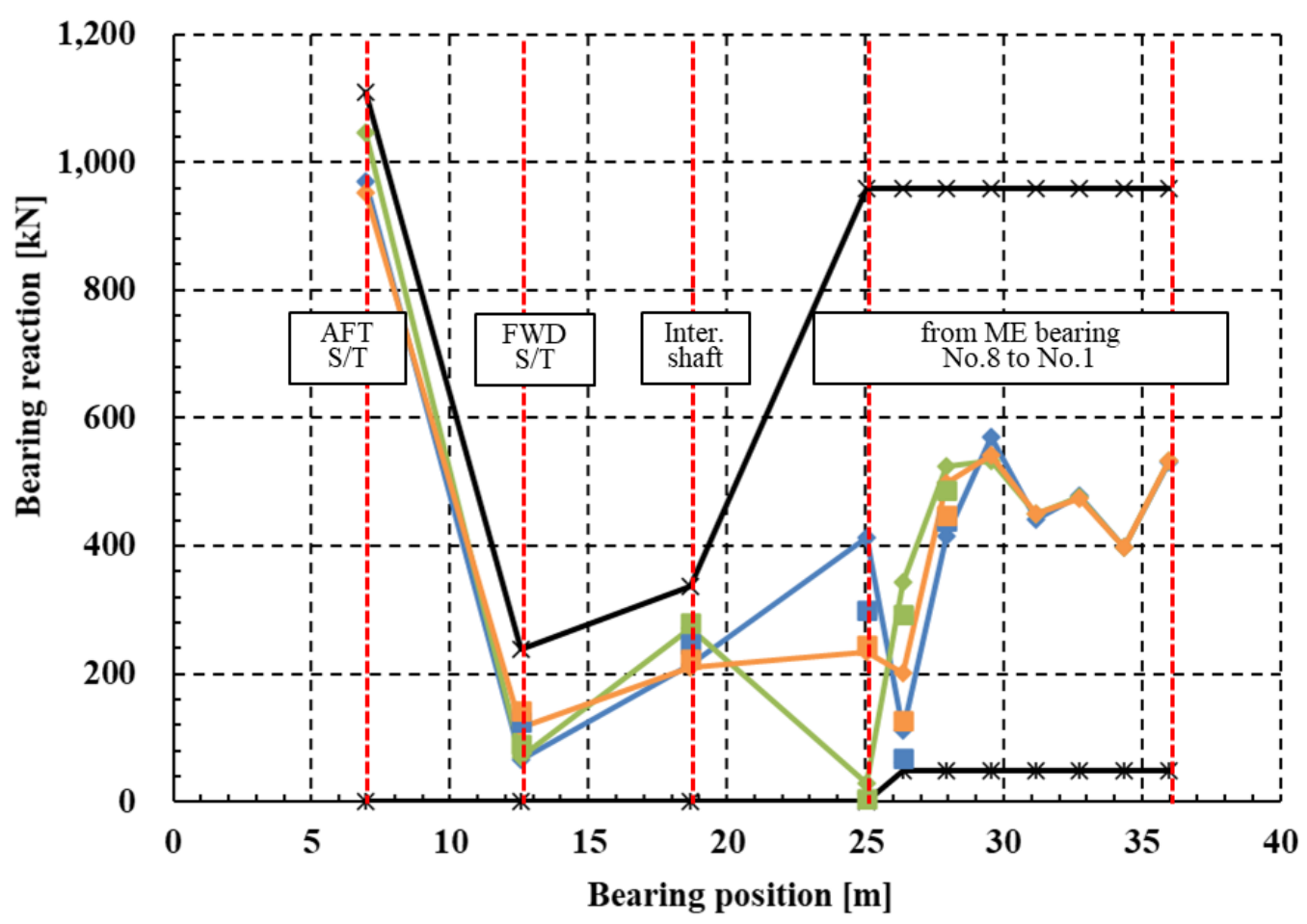

Fig. 17. Correlation between two methods at each alignment condition.

In the alignment (St1) condition, the assumed draught was $4.118 \mathrm{~m}$ for the stern side and $3.525 \mathrm{~m}$ for the foreside, but the actual draught was slightly different, $4.4 \mathrm{~m}$ for the stern side and $3.7 \mathrm{~m}$ for the foreside.

This may be due to the difference between the design weight and the actual weight.

In this condition (St1), measurements were generally used to verify that the offset of the installed bearings is within tolerance, and then verified by reverse engineering. The analytical and measured values in FWD S/T bearing and the intermediate shaft bearing are found properly matched.

The reaction force of M/E No. 8 bearing can be accommodated by setting the load close to no-load state (within $9.8 \mathrm{kN}$ in practice) according to the engine manufacturer's recommendations. 
The analysis and measured values of FWD S / T bearings and intermediate bearings under the conditions of St3 and St4 agree well under most conditions, confirming the reliability of the analysis.

However, it can be seen that the deviation between the measured value and the analyzed value occurs in the $\mathrm{M} / \mathrm{E}$ bearings. The reaction force of the measured main engine crankshaft bearing has deviation is different from the analysis results.

This is because the crankshaft model provided by the engine manufacturer is a two-dimensional model that does not reflect the bending stiffness of the actual crankshaft web. Analytical and measurement errors due to the effect of RIN (effect factor) on M/E-bearings are presumed to be such a cause. Moreover, it is also worth noting that the capability of shipyard workers who were assigned for the shaft arrangement as well as the yard-dock condition and sea states during the measurement might also have an influence on those deviations to some extent.

Nevertheless, in all conditions, the reaction force variation of the $\mathrm{M} / \mathrm{E}$ bearing is placed within the allowable value, so it is not considered to have an adverse effect on the crankshaft bearing.

In the future, further investigation will be needed to determine the cause of the deviation between the crankshaft measurements and the analysis results through accurate crankshaft model analysis.

\section{Concluding remark}

Throughout analysis, research findings can be summarised as below:

1) Hull deformation is found a key important factor affecting each bearing offset supporting the propulsion shafting system. Therefore, it confirms that such an effect should be taken into account in the shaft alignment analysis.

2) Results of finite element analysis revealed that the deformation pattern in response to the draught change had showed the opposite trend for two sections: first section is the engine room ranging from the engine room bulkhead (FR \# 60) containing the cargo hold to the fore bulkhead (FR \# 110); the second section ranged from the stern end where the shafting system 
is installed to the engine room bulkhead. That is, when the hull is deformed to the hogging state, the engine compartment part is deformed to the sagging state, and when the hull is deformed to the sagging state, the engine compartment part is deformed to the hogging state. It was confirmed that the hull deformed to the hogging state in the alignment draught condition, and the engine compartment part to be the sagging state, while the hull deformed to the sagging state and engine compartment to be the hogging state in the full draught condition. Such a finding - the opposite deformation pattern between the hull and the engine room - is highly believed to provide practical insights for ship designers to improve the reliability of the shaft alignment.

3) By using bearing offset determined from converting the hull deformations, it was found that the relative displacement from the light load to the full load shows that the shafting system would be affected by the hull deformation. It was confirmed that the shafting system was shifted from the right upward to the right downward.

4) As a result, the reaction force change of the shaft support bearing was characterized by the following reaction force change.

- The reaction force decreases in the aft stern tube bearing, intermediate shaft bearing and M/E No.7 bearing, while the force increases in the forward stern tube bearing and $\mathrm{M} / \mathrm{E}$ No. 8 bearing.

- In M/E No 5 to No.8 bearings, the variation of reaction force was significant depending on whether the ballast water was loaded or not in the aft peak tank. On the other hand, reaction force of M/E No.1 4 bearings was not affected by draught change.

5) The effectiveness of the proposed approach for the analysis was confirmed by comparing the analysis results with the measured values.

6) However, the relative deviation between the measured and analyzed values in the $\mathrm{M} / \mathrm{E}$ bearings is presumed to be due to the influence of the web bending stiffness of the crankshaft, the analytical error and the measurement error of the RIN. Therefore, further investigation is needed to confirm this cause. 
7) In the case of very large crude oil carriers, unlike small and medium sized ships, the ship has a long hull and a drastic change in draught according to loading conditions. It is considered that it is necessary to carry out the shaft alignment by considering the hull deformation.

8) In addition, if the ship hull deformation and its trends derived from this study can be referenced in the future shaft alignment analysis for similar ships. Therefore, it is highly believed to contribute to enhancing the shaft stability while preventing the shaft damage due to hull deformation.

\section{Acknowledgement}

This paper is a part of Ph.D. work done by the author. The author would like to thank Korea Maritime and Ocean University (KMOU) and Daewoo Shipbuilding \& Marine Engineering Co., Ltd. (DSME) for their valuable suggestion, supervision, and comments. Their support has significantly improved the quality of this paper. This study was supported by the Korean Research Foundation (NRF) sponsored by the Korean government (MSIP: Ministry of Science, ICT \& Future Planning; No. NRF2017R1C1B5017114).

\section{References}

Rudolph, M., 1959. A quarter century of propulsion shafting design practice and operating experience in the U.S. navy. J. American Soc. Nav. Eng. 71 (1), 153-164.

Anderson, H. C., Zrodowski, J. J., 1959. Co-ordinated alignment of line shaft, propulsion gear, and turbines. Annual meeting of Soc. Nav. Archit. Mar. Eng. 449-523.

Lehr, W. E., Parker, E. L., 1961. Considerations in the design of marine propulsion shaft systems. Int. J. Soc. Nav. Archit. Mar. Eng. 69, 555-601. 
Mann, G., 1964. Design of propulsion shaft systems using fair curve alignment theory. American Soc. Nav. Eng. J. 76(6), 851-862.

Mann, G., 1965a. Analysis of shafting problems using fair curve alignment theory. American Soc. Nav. Eng. J. 77(1), 117-133.

Mann, G., 1965b. Shipyard alignment of propulsion shafting using fair curve alignment theory. American Soc. Nav. Eng. J. 77(4), 651-659.

Mott, I. K., et al., 1967. Design aspects of marine propulsion shafting systems. Inst. Mar. Engrs. Trans. 79, 177.

Wilkin, T. A., Strassheim, W., 1973. Some theoretical and practical aspects of shaft alignment. IMAS Conference 73. Inst. Mar. Engrs. [Online]. Available: http://trid.trb.org/view.aspx?id=11182, Accessed July 22, 2019.

Jeon, H.J., Park, J. G., Choi, J. S., 1978. Optimum alignment of marine engine shaftings by the finite element method (in Korean). J. Korean Soc. Mar. Eng. 2(1), 3-14.

Park, T. I., Lee, H. Y., 1979. Alignment calculation of marine engine shafting system by quadruple integration method (in Korean). J. Korean Soc. Mar. Eng. 3(1), 32-39.

Moon, D. H., Jeon, J. H., 1981. A study on the propulsion shaft alignment calculation by the matrix method of three-moment theory (in Korean). J. Korean Soc. Mar. Eng. 5(1), 20-27.

Det Norske Veritas (DnV), 1975. Computer Program NV 540 Shaft Alignment User's Manual. Preliminary Version, Norway.

Doikos, A., 1979. Study of Strength and Alignment of a Marine Shafting System. Diploma Thesis. National Technical University of Athens, Greece.

Larsen, O. C., 1981a. Some considerations on marine shafting design. J. Industrial Lubrication Tribol. 33(5), 164171.

Larsen, O. C., 1981b. Some considerations on marine shafting design. J. Industrial Lubrication Tribol. 33(6), 204237. 
Jeon, H. J., 1986. Ship Propulsion Transmission Equipment (in Korean). Taewha Publishing Company, Busan, Korea.

SNAME, 2007. Practices and Procedures for the Alignment of Marine Main Propulsion Shafting Systems.

MAN Dieset \& Turbo (MDT), 2012. Bearing Load Measurement by Jacking Up.

Grant, R. B., 1980. Shaft alignment methods with strain gages and load cells. Mar. Tech. 17(1), 8-15.

Forrest, A. W., Labasky, R. F., 1981. Shaft alignment using strain gages. Mar. Tech. 18(3), 276-284.

Cowper, B., DaCosta, A., Bobyn, S., 1999. Shaft alignment using strain gages: case studies. Mar. Tech. 36(2), 7791.

Kozousek, V. M., Davies, P. G., 2000. Analysis and Survey Procedures of Propulsion Systems: Shaft Alignment. LR Technical Association. 5, 1-24.

Nippon Kaiji Kyokai (NK), 2006. Guidelines on Shafting Alignment. NK, Japan.

MAN Dieset \& Turbo (MDT), 2014. Crankshaft Deflection Shop Trial and Sea Trial / Site Trial, Acceptance Criteria. Denmark.

Wärtsilä, 2007. Amendment and Update of the Information Provided in Design Group 9709 “Engine Alignment”. Switzerland.

DnV, 2006. The Effect of Hydrodynamic Propeller Load on the Shaft Alignment of a VLCC., Hovik, Norway.

Sverko, D., 2003. Design concerns in propulsion shafting alignment. ABS Technical Papers 1-13.

Sverko, D., 2005. Hull deflections shaft alignment interaction, a case study. In: Proceedings of the 7th International Symposium on Marine Engineering, pp.245-251.

Lee, Y. J., Kim, U. K., 2005a. A study on hull deflection and shaft alignment interaction in VLCC. J. Korean Soc. Mar. Eng. 29(7), 785 794. 
Lee, Y. J., Kim, U. K., 2005b. An analysis of hull deflection using bending moments and bearing reaction forces of bulk carrier shafting system (in Korean). In: Proceedings of the Annual Autumn Meeting, J. Korean Soc. Mar. Eng. pp. 6-7.

Lee, Y. J., Lee, H. K., Kim, U. K., 2005. An analysis of hull deflection for propulsion shaft alignment of a 46,000 DWT oil/chemical carrier (in Korean). In: Proceedings of the Annual Autumn Meeting, J. Korean Soc. Mar. Eng. pp. 1-2.

Lee, Y. J., Kim, U. K., Kim, J. S., 2006. Hull deflections affecting on the ship's propulsion shafting alignment in 64k oil/chemical carrier. J. Korean Soc. Mar. Eng. 30(7), 800-807.

Lee, Y. J., 2006. A Study on Hull Deflections Effecting the Ship's Propulsion Shafting Alignment (in Korean). Ph.D., Department of Mechanical Engineering Graduate School, Korea Maritime and Ocean University, Korea. Lei, S., Dongxin, X., Xigeng, S., 2010. Research on shafting alignment considering ship hull deformations. Mar. Struct. 23(1), 103-114.

Murawski, L., 2005. Shaft line alignment analysis taking ship construction flexibility and deformations into consideration. Mar. Struct. 18(1), 62-84.

American Bureau of Shipping (ABS), 2006. Guidance Notes on Propulsion Shafting Alignment. NY, USA.

Bureau Veritas (BV), 2015. Elastic shaft alignment (ESA).

American Bureau of Shipping (ABS), 2018. Enhanced Shaft Alignment.

DNVGL, 2019. Part 4 Systems and components, Chapter 2 Rotating machinery general 2.1.6 Aft most bearing lubrication criteria.

Bradshaw, R., 1995. The mechanics of shaft alignment. Intl. Shipbuilding. Progress. 42(430), 132-161.

Dufrane K. F., Kannel J. W., McCloskey, T. H., 1983. Wear of steam turbine journal bearings at low operating speeds. J. Lubrication Tech. (105), 313-317.

Khonsari, M. M., Booser, E. R., 2008. Applied Tribology Bearing Design and Lubrication. Second edition, John Wiley and sons. 
Lee, J. U., 2018. Application of strain gauge method for investigating influence of ship shaft movement by hydrodynamic propeller forces on shaft alignment. Measurement. 121, 261-275.

Choung, J. M., Choe, I. H., Shin, S. H., 2005. A study on elastic shaft alignment using nonlinear bearing elements. J. Soc. Naval Archit. Korea. 42(3), 259-267.

Choung, J. M., Choe, I. H., Shin, S. H., 2004. Elastic shaft alignment design and analysis considering hull deflection (in Korean). In: Proceedings of the Annual Autumn Meeting, J. Soc. Naval Archit. Korea, 870-877.

Shin, S. H., Choe, I. H., 2004. Pressure distribution ananlysis for after bush bearing of ship propulsion shaft (in Korean). J. Soc. Naval Archit. Korea. 41(3), 35-40.

Choung, J. M., Choe, I. H., 2007. Pressure analysis of sterntube after bush bearing considering elastic deflection of misaligned journal and partial slope of bearing bush (in Korean). J. Soc. Naval Archit. Korea. 44(6), 666-674.

Lee, J. U., 2016a. A case study on the optimal shafting alignment concerning bearing stiffness for 10,100 TEU container carrier (in Korean). J. Korean Soc. Mar. Eng. 40(3), 185-190.

Lee, J. U., 2016b. A Study on the Analysis Shaft Alignment Considering Hull Deflections for 50,000 DWT Oil/Chemical Tanker (in Korean). J. Korean Soc. Mar. Eng. 40(3), 191-197.

Saitoh, T., 1983. Dynamic alignment taking account of propeller forces and stern tube bearing performances. J. Mar. Eng. Soc. Jpn.18(2), 142-153.

Kuroiwa, R., Oshima, A., Nishioka, T., Tateishi, T., Ohyama, K., Ishijima, T., 2007. Reliability improvement of stern tube bearing considering propeller shaft forces during ship turning. Mitshbishi Heavy Industries, Ltd. Technical Review. 44(3), 1-3.

Takahashi, S., Matsumoto, S., Tateishi, T., Ohyama, K., Kuroiwa, R., Morohoshi, S., 2009. Study on oil film analysis of the stern tube bearing under the conditions of dynamic propeller shaft forces. Jpn. Soc. Mechanical Engineers. Trans. C75(759), 3054-3061.

Vartdal, B. J., Gjestland, T., Arvidsen, T. I., 2009. Lateral propeller forces and their effects on shaft bearings. In: First International Symposium on Marine Propulsors, Trondheim, Norway, 475-481. 
Shin, S. H., 2015. Effects of propeller forces on the propeller shaft bearing during going straight and turning ship (in Korean). J. Soc. Naval Archit. Korea. 52(1), 61-69.

Lee, J. U., Jeong, B. U., An, T. H., 2019. Investigation on effective support point of single stern tube bearing for marine propulsion shaft alignment. Mar. Struct. 64, 1-17.

Sun, J. S., 2017. A Study on Shaft Alignment of Propulsion Shafting System Depending on Reaction Supporting Position and Slope of Aft Stern Tube Bearing (in Korean). Ph. D., Department of Mechanical Engineering, Korea Maritime and Ocean University, Korea.

Huang, Q., Yan, X., Wang, Y., Zhang, C., Wang, Z., 2017. Numerical modelling and experimental analysis on coupled torsional-longitudinal vibrations of a ship's propeller shaft. Ocean Eng. 136, 272-282.

Huang, Q., Yan, X., Zhang, C., Zhu, H., 2019. Coupled transverse and torsional vibrations of the marine propeller shaft with multiple impact factors. Ocean Eng. 178, 48-58.

Xie, X., Qin, H., Xu, Y., Zhang, Z., 2019. Lateral vibration transmission suppression of a shaft-hull system with active stern support. Ocean Eng. 172, 501-510. 